Ruiz-Córdoba, I.C. (2018). Ciudades campamento y tierras desoladas. El caso de Antioquia 1997-2013.

Revista de Antropología y Sociología: VIRAJES, 20(2), 95-124. DOI: 10.17151/rasv.2018.20.2.6.

\title{
Ciudades campamento y tierras desoladas. El caso de Antioquia 1997 - 2013
}

\section{ISABEL CRISTINA RUIZ-CÓRDOBA*}

Recibido: 10 de agosto de 2017 Aprobado: 4 de diciembre de 2017

Artículo de Investigación

\footnotetext{
* Magíster en Estudios Políticos: Facultad de Ciencias Humanas y Económicas. Universidad Nacional de Colombia. E-mail: icruizc@unal.edu.co @ ORCID: 0000-0001-8854-8203. Google Scholar
} 


\title{
Resumen
}

El artículo presenta los datos principales para el departamento de Antioquia arrojados por el Censo Nacional Agropecuario confrontados con la reconfiguración poblacional de la movilidad producida por los desplazamientos ocurridos en el departamento desde finales de la década de los años noventa, que cambió los escenarios rurales y urbanos, dado que dejó un campo más empobrecido por la ausencia y el envejecimiento de los trabajadores rurales y la reconfiguración de la tenencia de la tierra, a la vez que incidió en el establecimiento de las dinámicas urbanas actuales en Medellín, su área metropolitana y las tres aglomeraciones existentes en Antioquia.

Palabras clave: desplazamiento forzado, desarrollo rural, conflicto armado, territorialidad en Antioquia, víctimas.

\section{Camps cities and desolate lands. The case of the department of Antioquia between 1997-2013}

\begin{abstract}
The article presents the main data released by the National Agricultural Survey for the department of Antioquia, compared with the population changes as a result of the mobility produced by forced displacement that occurred in this Department since the end of the 1990's which changed the rural and urban scenarios given that it left more impoverished land due to the absence and aging of the rural workers, as well as their configuration of land tenure, while at the same time influencing the establishment of the current urban dynamics in Medellin, in its metropolitan area and in the three existing peripheral urban centers in Antioquia.
\end{abstract}

Key words: forced displacement, rural development, Colombian conflict, Territoriality on the Department of Antioquia, victims. 


\section{Consideraciones conceptuales}

\section{A. Territorialidad}

n Antioquia existen dos puntos nodales del sistema de
ciudades: Medellín que aglomera a los municipios de Barbosa,
Bello, Caldas, Copacabana, Envigado, Girardota, Itagüí, La Estrella y Sabaneta; y Rionegro que aglomera los municipios de El Carmen de Viboral, Guarne, La Ceja y Marinilla. Además, en el departamento se identifican dos municipios con función subregional: Turbo y Caucasia. Se consideran intermedios los municipios entre 25 y 100 mil habitantes o que tienen alta densidad poblacional (mayor a $10 \mathrm{hab} / \mathrm{km}^{2}$ ) (DDRS, 2014).

Son habitantes rurales los de los municipios con cabeceras de menos de 25 mil habitantes y bajas densidades de población y los municipios clasificados como rurales dispersos, que concentran en sus cabeceras una cantidad menor de habitantes con densidades poblacionales muy bajas. Los resultados para las clasificaciones en Colombia se aprecian en el siguiente cuadro descriptivo:

Tabla 1. Categorías de ruralidad en Colombia

\begin{tabular}{|c|c|c|c|c|c|}
\hline & & \multicolumn{4}{|c|}{ Población en cabecera (miles) } \\
\hline & & \multirow[b]{2}{*}{$\begin{array}{c}\text { Más de } 100 \text { (Ciudades y } \\
\text { aglomeraciones) }\end{array}$} & \multirow[b]{2}{*}{25 a 100} & \multicolumn{2}{|c|}{ Menos de 25} \\
\hline & & & & $\begin{array}{c}<70 \% \text { de la } \\
\text { población en } \\
\text { zona resto }\end{array}$ & $\begin{array}{c}>70 \% \text { de la } \\
\text { población en zona } \\
\text { resto }\end{array}$ \\
\hline \multirow{4}{*}{ 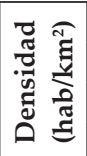 } & $>100$ & \multirow{4}{*}{117} & 29 & 84 & 35 \\
\hline & $50-100$ & & 19 & 132 & 91 \\
\hline & $10-50$ & & 15 & 279 & 203 \\
\hline & $0-10$ & & 3 & 54 & 61 \\
\hline
\end{tabular}

\begin{tabular}{|l} 
Ciudades y aglomeraciones \\
Intermedios \\
Rural \\
Rural disperso
\end{tabular}

Fuente: Tomado de DDRS (2014) en el marco de la Misión para la Transformación del Campo

De acuerdo con los datos anteriores, el $61,6 \%$ de los municipios del país son rurales, lo que está en correspondencia con el 64,9\% del territorio que ocupan. El fenómeno de concentración de la población en los últimos años en los centros urbanos, está directamente relacionado con la 
violencia; no obstante, gran parte de la población que habita las ciudades y aglomeraciones, dado lo reciente delos procesos de urbanización, pertenecen a la primera o segunda generación de campesinos migrantes, de allí, que las características dadas por las dinámicas culturales, sociales y ambientales de la ruralidad del país, sean determinantes del ethos colombiano (Conferencia Episcopal de Colombia, Universidad de Antioquia, 2001).

La población antioqueña es de conformación pluriétnica que territorialmente ha sido dividida en nueve subregiones: el Valle de Aburrá, donde se concentra el $59 \%$ de la población total del departamento y que está conformada por 10 municipios; allí se encuentran las principales localidades incluyendo la capital, Medellín, de vocación industrial, pero en los últimos años promocionada como ciudad de servicios, su población es mayoritariamente mestiza (Restrepo, 2016).

El Bajo Cauca antioqueño es una región ubicada cerca de la desembocadura del río Cauca, está conformada por seis municipios y su economía depende de la explotación y el comercio de oro, gran parte de la población es afrodescendiente, mulata y mestiza; allí se concentra el $5 \%$ de la población.

La subregión de Magdalena Medio tiene seis municipios, es una zona de vocación ganadera donde vive aproximadamente el $2 \%$ de la población. La subregión del Nordeste, de profunda vocación minera, está compuesta por diez municipios, sus habitantes son en su mayoría afrodescendientes y mestizos, concentra un poco menos del $3 \%$ de la población. La subregión Norte con 17 municipios, es de conformación mayoritariamente mestiza, su vocación es agrícola y extensiva en ganadería de leche, su territorio concentra el $4 \%$ de la población.

En las regiones de Suroeste y Oriente se ubican 47 municipios en zonas de cordillera. El Suroeste es de vocación agrícola con población mayoritariamente blanca y mestiza, el $6 \%$ de la población total y cultural e históricamente identificada con el poblador originario de la región. En Oriente se ubica la zona de embalses que concentra el $35 \%$ de la generación eléctrica nacional, su población es de características étnicas blanco-mestizas y es la tercera zona más poblada del departamento después del Valle de Aburra y Urabá. En Occidente se encuentran 19 municipios, con población étnica y culturalmente diversa; junto a la subregión de Urabá, concentra la mayor cantidad de indígenas del departamento; en ella habita poco más del $3 \%$ de la población y es de vocación agrícola y minera (Gobernación de Antioquia et al., 2013).

Especial atención merece la subregión de Urabá, tiene 11 municipios que se localizan en tres territorios zonificados según sus características geográficas, sociales y de poblamiento; concentra la mayor población 
afrodescendiente de Antioquia y una cantidad muy importante de comunidades indígenas. Económica y geoestratégicamente es una zona de enorme proyección para el departamento y para el país; de base económica agraria extensiva; es la segunda subregión con más habitantes; casi el 10 $\%$ de la población. Fue una de las regiones más golpeadas por la violencia insurgente y contrainsurgente; bajo una primera mirada, exhibe, en el territorio de Antioquia, todas las condiciones para que sea priorizada en el marco de la implementación del acuerdo. El fenómeno del desplazamiento forzado ha sido padecido con particular intensidad en Urabá. Se podría inferir que existe una relación positiva entre los fenómenos de tenencia de la tierra y el desplazamiento forzado, en ella se concentra buena parte de la producción agrícola y es una de las de mayor desarrollo de la agroindustria en el país (Grupo de Memoria Histórica, 2013).

El origen de la agroindustria en Urabá se da alrededor del banano, se produjeron los primeros cultivos en el año de 1900 con una concesión que se le dio a la empresa alemana Albingia, posteriormente hacia 1914, ésta abandonó el cultivo por causas de la primera guerra mundial, sin embargo, alcanzaron a tener 5.000 hectáreas sembradas, un muelle de 200 metros y un ferrocarril de 20 kilómetros (Restrepo, 2013). Luego, el banano desapareció de la escena económica regional hasta 1960 cuando se estableció una plantación ya tecnificada por la United Fruit Company bajo un modelo alternativo desde el punto de vista de la propiedad, invitaron a particulares dueños de la tierra y les ofrecieron proveer la tecnología y la asistencia técnica; les vendieron los abastecimientos, suministros y otros insumos además de facilitarles el acceso al crédito, pero manteniéndolos controlados bajo los contratos de comercialización.

Las nuevas condiciones significaron que hacia 1964 los bananeros propietarios de las tierras iniciaran un movimiento que culminó en 1969 con la creación de nuevos instrumentos de comercialización directa a través de las agremiaciones que se conocen hoy como Uniban, Banacol y Proban. Éstas comercializaban la fruta de sus afiliados lo que condujo a que las compañías norteamericanas desaparecieran. Actualmente esas mismas asociaciones controlan la comercialización ${ }^{1}$.

En el departamento de Antioquia, según la conceptualización territorial, los municipios están clasificados como relaciona a continuación.

\footnotetext{
${ }^{1}$ En el segundo semestre del año 2013, Nicanor Restrepo Santamaría dictó en la facultad de Ciencias Humanas y Económicas de la Universidad Nacional-Sede Medellín el curso Sociedad y Economía en Antioquia en el siglo XX. Este relato hace parte de algunos de los audios grabados de las sesiones.
} 
Tabla 2. Ciudades y aglomeraciones en Antioquia

\begin{tabular}{llr}
\multicolumn{1}{c}{ SUBREGIÓN } & \multicolumn{1}{c}{ MUNICIPIO } & $\begin{array}{r}\text { POBLACIÓN } \\
\text { TOTAL 2015 }\end{array}$ \\
\hline BAJO CAUCA & Caucasia & $\mathbf{1 1 2 . 1 6 8}$ \\
\hline ORIENTE & Rionegro & $\mathbf{1 2 0 . 2 4 9}$ \\
\hline URABÁ & Apartadó & $\mathbf{1 7 8 . 2 5 7}$ \\
\hline URABÁ & Turbo & $\mathbf{1 5 9 . 2 6 8}$ \\
\hline VALLE DE ABURRA & Barbosa & 50.050 \\
\hline VALLE DE ABURRA & Bello & $\mathbf{4 5 5 . 8 0 7}$ \\
\hline VALLE DE ABURRA & Caldas & $\mathbf{7 7 . 8 5 4}$ \\
\hline VALLE DE ABURRA & Copacabana & $\mathbf{2 2 2 . 4 1 0}$ \\
\hline VALLE DE ABURRA & Envigado & 54.219 \\
\hline VALLE DE ABURRA & Girardota & $\mathbf{2 6 7 . 8 7 2}$ \\
\hline VALLE DE ABURRA & Itagüí & $\mathbf{6 2 . 3 4 4}$ \\
\hline VALLE DE ABURRA & La Estrella & $\mathbf{2 . 4 6 4 . 3 2 2}$ \\
\hline VALLE DE ABURRA & Medellín & $\mathbf{5 1 . 8 6 8}$ \\
\hline VALLE DE ABURRA & Sabaneta & \\
\hline & & \\
\hline
\end{tabular}

Fuente: Elaboración propia con base en la información de DDRS-DNP en el marco de la Misión para la Transformación del Campo

(Definición de Categorías de Ruralidad, 2014)

Tabla 3. Municipios intermedios ${ }^{3}$

\begin{tabular}{llr}
\hline \multicolumn{1}{c}{ SUBREGIÓN } & \multicolumn{1}{c}{ MUNICIPIO } & \multicolumn{2}{c}{$\begin{array}{r}\text { POBLACIÓN } \\
\text { TOTAL }\end{array}$} \\
\hline BAJO CAUCA & El Bagre & 49.583 \\
\hline MAGDALENA MEDIO & Puerto Berrío & 46.883 \\
\hline MAGDALENA MEDIO & Puerto Triunfo & 20.062 \\
\hline NORDESTE & Cisneros & 9.058 \\
\hline SUROESTE & Santa Bárbara & 22.076 \\
\hline NORDESTE & Segovia & 40.174 \\
\hline OCCIDENTE & Heliconia & 5.906 \\
\hline OCCIDENTE & San Jerónimo & 12.635 \\
\hline ORIENTE & El Carmen de Viboral & 46.751 \\
\hline ORIENTE & El Santuario & 27.120 \\
\hline ORIENTE & Granada & 9.859 \\
\hline
\end{tabular}

${ }^{2}$ Datos tomados de Proyecciones de Población Nacionales y Departamentales 2006-2020 (2015).

${ }^{3}$ Datos tomados de Proyecciones de Población Nacionales y Departamentales 2006-2020 (2015).

100 | antropol.sociol. Vol. 20 No. 2, julio - diciembre 2018, págs. 95-124 | 


\begin{tabular}{|c|c|c|}
\hline SUBREGIÓN & MUNICIPIO & $\begin{array}{l}\text { POBLACIÓN } \\
\text { TOTAL } 2015^{3}\end{array}$ \\
\hline ORIENTE & Guarne & 47.797 \\
\hline ORIENTE & Guatapé & 5.279 \\
\hline ORIENTE & La Ceja & 52.723 \\
\hline ORIENTE & La Unión & 19.119 \\
\hline ORIENTE & Marinilla & 53.374 \\
\hline ORIENTE & Peñol & 15.889 \\
\hline ORIENTE & Retiro & 19.108 \\
\hline ORIENTE & San Vicente & 17.197 \\
\hline REGIÓN NORTE & Don Matías & 22.243 \\
\hline REGIÓN NORTE & Guadalupe & 6.300 \\
\hline REGIÓN NORTE & San Pedro & 26.592 \\
\hline REGIÓN NORTE & Yarumal & 46.865 \\
\hline SUROESTE & Amagá & 29.555 \\
\hline SUROESTE & Andes & 45.814 \\
\hline SUROESTE & Angelópolis & 8.946 \\
\hline SUROESTE & Betania & 9.286 \\
\hline SUROESTE & Betulia & 17.542 \\
\hline SUROESTE & Caramanta & 5.362 \\
\hline SUROESTE & Ciudad Bolívar & 27.084 \\
\hline SUROESTE & Concordia & 20.653 \\
\hline SUROESTE & Fredonia & 21.561 \\
\hline SUROESTE & Hispania & 4.869 \\
\hline SUROESTE & Jardín & 13.748 \\
\hline SUROESTE & Jericó & 12.103 \\
\hline SUROESTE & La Pintada & 6.558 \\
\hline SUROESTE & Montebello & 6.197 \\
\hline SUROESTE & Pueblorrico & 7.030 \\
\hline URABÁ & Arboletes & 40.147 \\
\hline URABÁ & Carepa & 55.788 \\
\hline URABÁ & Chigorodó & 76.202 \\
\hline URABÁ & San Juan de Urabá & 25.168 \\
\hline URABÁ & San Pedro de Urabá & 31.280 \\
\hline
\end{tabular}

Fuente: Elaboración propia con base en la información de DDRS-DNP en el marco de la Misión para la Transformación del Campo (Definición de Categorías de Ruralidad, 2014) 
Tabla 4. Municipios rurales

\begin{tabular}{|c|c|c|}
\hline SUBREGIÓN & MUNICIPIO & $\begin{array}{l}\text { POBLACIÓN } \\
\text { TOTAL } 2015^{4}\end{array}$ \\
\hline BAJO CAUCA & Nechí & 26.591 \\
\hline BAJO CAUCA & Zaragoza & 30.738 \\
\hline MAGDALENA MEDIO & Caracolí & 4.595 \\
\hline MAGDALENA MEDIO & Maceo & 6.855 \\
\hline MAGDALENA MEDIO & Puerto Nare & 18.654 \\
\hline NORDESTE & Amalfi & 22.088 \\
\hline NORDESTE & Anorí & 17.086 \\
\hline NORDESTE & Remedios & 29.199 \\
\hline NORDESTE & San Roque & 16.789 \\
\hline NORDESTE & Vegachí & 9.448 \\
\hline NORDESTE & Yalí & 8.318 \\
\hline NORDESTE & Yolombó & 23.958 \\
\hline OCCIDENTE & Armenia & 4.210 \\
\hline OCCIDENTE & Cañasgordas & 16.763 \\
\hline OCCIDENTE & Dabeiba & 23.378 \\
\hline OCCIDENTE & Ebéjico & 12.515 \\
\hline OCCIDENTE & Frontino & 16.615 \\
\hline OCCIDENTE & Giraldo & 4.029 \\
\hline OCCIDENTE & Sabanalarga & 8.191 \\
\hline OCCIDENTE & Sopetrán & 14.696 \\
\hline OCCIDENTE & Santafé de Antioquia & 24.549 \\
\hline OCCIDENTE & Uramita & 8.238 \\
\hline ORIENTE & Abejorral & 19.290 \\
\hline ORIENTE & Alejandría & 3.466 \\
\hline ORIENTE & Cocorná & 14.972 \\
\hline ORIENTE & Concepción & 3.463 \\
\hline ORIENTE & Nariño & 17.291 \\
\hline ORIENTE & San Carlos & 16.064 \\
\hline ORIENTE & San Francisco & 5.318 \\
\hline ORIENTE & San Luis & 10.939 \\
\hline ORIENTE & San Rafael & 12.980 \\
\hline
\end{tabular}

${ }^{4}$ Datos tomados de Proyecciones de Población Nacionales y Departamentales 2006-2020 (2015).

102 | antropol.sociol. Vol. 20 No. 2, julio - diciembre 2018, págs. 95-124 | 


\begin{tabular}{llr}
\hline \multicolumn{1}{c}{ SUBREGIÓN } & \multicolumn{1}{c}{ MUNICIPIO } & $\begin{array}{r}\text { POBLACIÓN } \\
\text { TOTAL 2015 }\end{array}$ \\
\hline ORIENTE & Sonsón & 35.405 \\
\hline REGIÓN NORTE & Campamento & 9.091 \\
\hline REGIÓN NORTE & Carolina & 3.629 \\
\hline REGIÓN NORTE & Entrerríos & 9.950 \\
\hline REGIÓN NORTE & Gómez Plata & $\mathbf{1 2 . 8 1 0}$ \\
\hline REGIÓN NORTE & San Andrés de Cuerquia & 6.226 \\
\hline REGIÓN NORTE & San José de La Montaña & 3.336 \\
\hline REGIÓN NORTE & Santa Rosa de Osos & 35.650 \\
\hline SUROESTE & Támesis & $\mathbf{1 4 . 7 3 2}$ \\
\hline SUROESTE & Tarso & 7.776 \\
\hline SUROESTE & Titiribí & $\mathbf{1 4 . 3 9 3}$ \\
\hline SUROESTE & Venecia & $\mathbf{1 3 . 2 5 3}$ \\
\hline SUROESTE & Salgar & $\mathbf{1 7 . 6 0 8}$ \\
\hline SUROESTE & Urrao & 44.648 \\
\hline SUROESTE & Valparaíso & 6.174 \\
\hline
\end{tabular}

Fuente: Elaboración propia con base en la información de DDRS-DNP en el marco de la Misión para la Transformación del Campo (Definición de Categorías de Ruralidad, 2014)

Tabla 5. Municipios área rural dispersa

\begin{tabular}{llr}
\hline \multicolumn{1}{c}{ SUBREGIÓN } & \multicolumn{1}{c}{ MUNICIPIO } & $\begin{array}{l}\text { POB L A CIÓ N } \\
\text { TOTAL 2015 }\end{array}$ \\
\hline BAJO CAUCA & Cáceres & 37.806 \\
\hline BAJO CAUCA & Tarazá & $\mathbf{4 2 . 6 4 1}$ \\
\hline MAGDALENA MEDIO & Yondó & $\mathbf{1 8 . 6 1 3}$ \\
\hline NORDESTE & Santo Domingo & $\mathbf{1 0 . 4 1 6}$ \\
\hline OCCIDENTE & Abriaquí & $\mathbf{2 . 1 2 8}$ \\
\hline OCCIDENTE & Anzá & 7.568 \\
\hline OCCIDENTE & Buriticá & 6.601 \\
\hline OCCIDENTE & Caicedo & 8.205 \\
\hline OCCIDENTE & Liborina & 9.535 \\
\hline OCCIDENTE & Olaya & 3.237 \\
\hline
\end{tabular}

\footnotetext{
${ }^{5}$ Datos tomados de Proyecciones de Población Nacionales y Departamentales 2006-2020 (2015).
} 


\begin{tabular}{llr}
\hline \multicolumn{1}{c}{ SUBREGIÓN } & \multicolumn{1}{c}{ MUNICIPIO } & $\begin{array}{r}\text { POB L A CIÓ N } \\
\text { TOTAL 2015 }\end{array}$ \\
\hline OCCIDENTE & Peque & 10.925 \\
\hline ORIENTE & Argelia & 8.699 \\
\hline REGIÓN NORTE & Angostura & 11.354 \\
\hline REGIÓN NORTE & Belmira & 6.760 \\
\hline REGIÓN NORTE & Briceño & 8.702 \\
\hline REGIÓN NORTE & Ituango & 20.996 \\
\hline REGIÓN NORTE & Toledo & 6.374 \\
\hline REGIÓN NORTE & Valdivia & 22.179 \\
\hline URABÁ & Murindó & 4.593 \\
\hline URABÁ & Mutatá & 20.612 \\
\hline URABÁ & Necoclí & 62.365 \\
\hline URABÁ & Vigía del Fuerte & 5.586 \\
\hline
\end{tabular}

Fuente: Elaboración propia con base en la información de DDRS-DNP en el marco de la Misión para la Transformación del Campo (Definición de Categorías de Ruralidad, 2014)

Teniendo en cuenta la categorización entregada por la Misión para la Transformación del Campo y las proyecciones poblacionales del DANE; en Antioquia el $67 \%$ de los habitantes están asentados en ciudades y aglomeraciones en 14 municipios, la mayoría de ellos en el Valle de Aburrá a excepción de Caucasia, Turbo, Apartadó y Rionegro. El 17 \% viven en 43 municipios intermedios, un $11 \%$ en 46 municipios rurales, y el restante $5 \%$ en 22 municipios categorizados como áreas rurales dispersas.

\section{B. Desplazamiento}

En 2004 la Corte Constitucional por medio de la orden impartida en Sentencia T-025 declaró un estado de cosas inconstitucionales y conminó al gobierno a diseñar, formular y reglamentar una política pública de atención a la población desplazada (Corte Constitucional de Colombia, 2004); situación que sólo se materializó siete años después por medio de la promulgación de la Ley 1448. La Corte estableció que era necesario que esa atención humanitaria fuera diferencial, es decir que tuviera enfoques de etnia, género, grupo etáreo, etc. (Osorio y Lozano, 2014).

Acción social se convirtió en el ente coordinador de la atención y la ejecución de las políticas de atención y la creación y consolidación del Registro Único de población desplazada. A raíz de la expedición de la Ley 1190 de 2008, su posterior decreto reglamentario 1997 de 2009 y en 
el Auto 007 de 2009 de la Corte Constitucional, se le ordenó al gobierno incrementar el presupuesto destinado para la ayuda humanitaria y desplegar mayores herramientas para ese fin (Villa \& Insuasty, 2015). Ha sido preocupación de la Corte que el Estado pretenda delegar en los entes territoriales que no cuentan con los recursos para hacerlo, la atención de la población desplazada. El Gobierno hecho esfuerzos a nivel presupuestal para cumplir con los mandatos de la Corte, no obstante, éstos continúan siendo insuficientes ante el número de población desplazada y el impacto y presión de dichas migraciones, ante todo sobre las ciudades capitales y las aglomeraciones urbanas que fueron sus principales receptores.

\section{Resultados}

A continuación, se presenta el cuadro con los datos de población, desplazamiento y recepción en el departamento de Antioquia en el período indicado.

Tabla 6. Expulsión y recepción de población en el departamento de Antioquia en el período 1997 - 2013 por municipio

\begin{tabular}{|c|c|c|c|c|c|c|c|c|c|c|}
\hline 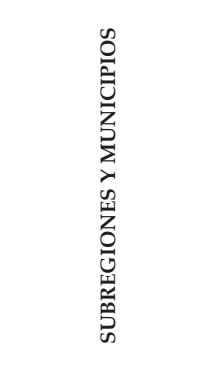 & 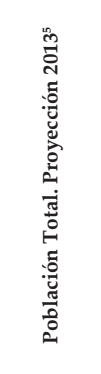 & 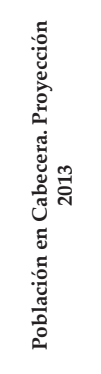 & 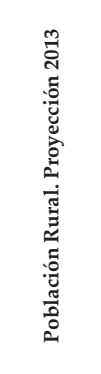 & 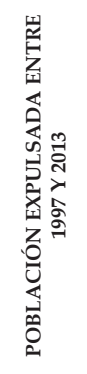 & 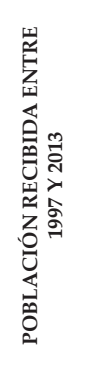 & 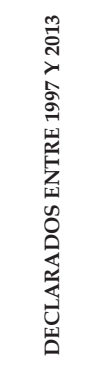 & 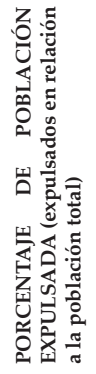 & 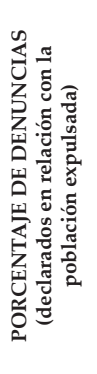 & 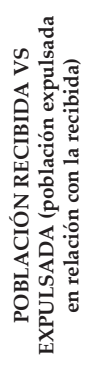 & 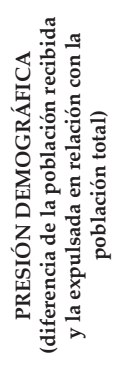 \\
\hline TOTAL DEPTO. & 6.299 .990 & 4.906 .419 & 1.393 .571 & 951.215 & 983.851 & 1.113 .955 & $15,1 \%$ & $117,1 \%$ & $103,4 \%$ & $0,5 \%$ \\
\hline VALLE DE ABURRÁ & 3.685 .382 & 3.506.224 & 179.158 & 102.411 & 399.321 & 387.562 & $2,8 \%$ & $378,4 \%$ & $389,9 \%$ & $8,1 \%$ \\
\hline Medellín & 2.417 .325 & 2.386 .233 & 31.092 & 88.007 & 338.070 & 334.543 & $3,6 \%$ & $380,1 \%$ & $384,1 \%$ & $10,3 \%$ \\
\hline Barbosa & 48.503 & 22.145 & 26.358 & 2.890 & 3.159 & 2.903 & $6,0 \%$ & $100,4 \%$ & $109,3 \%$ & $0,6 \%$ \\
\hline Bello & 438.577 & 430.576 & 8.001 & 5.427 & 33.811 & 28.900 & $1,2 \%$ & $532,5 \%$ & $623,0 \%$ & $6,5 \%$ \\
\hline Caldas & 75.984 & 59.623 & 16.361 & 995 & 2.442 & 2.442 & $1,3 \%$ & $245,4 \%$ & $245,4 \%$ & $1,9 \%$ \\
\hline Copacabana & 68.434 & 59.619 & 8.815 & 597 & 2.759 & 2.477 & $0,9 \%$ & $414,9 \%$ & $462,1 \%$ & $3,2 \%$ \\
\hline Envigado & 212.283 & 204.399 & 7.884 & 259 & 2.708 & 2.422 & $0,1 \%$ & $935,1 \%$ & $1045,6 \%$ & $1,2 \%$ \\
\hline Girardota & 51.782 & 30.912 & 20.870 & 570 & 1.452 & 1.207 & $1,1 \%$ & $211,8 \%$ & $254,7 \%$ & $1,7 \%$ \\
\hline
\end{tabular}

\footnotetext{
${ }^{6}$ Datos tomados de Proyecciones de Población Nacionales y Departamentales 2006-2020 (2015).
} 


\section{年}
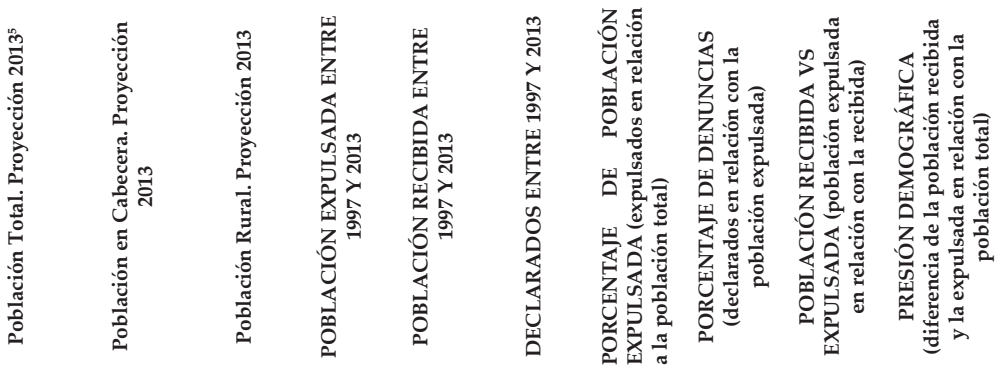

\begin{tabular}{|c|c|c|c|c|c|c|c|c|c|c|}
\hline Itagüí & 261.662 & 239.056 & 22.606 & 3.085 & 12.021 & 9.843 & $1,2 \%$ & $319,1 \%$ & $389,7 \%$ & $3,4 \%$ \\
\hline La Estrella & 60.388 & 33.466 & 26.922 & 395 & 1.907 & 1.756 & $0,7 \%$ & $444,6 \%$ & $482,8 \%$ & $2,5 \%$ \\
\hline Sabaneta & 50.444 & 40.195 & 10.249 & 186 & 992 & 1.069 & $0,4 \%$ & $574,7 \%$ & $533,3 \%$ & $1,6 \%$ \\
\hline BAJO CAUCA & 287.279 & 173.017 & 114.262 & 92.745 & 51.028 & 52.644 & $32,3 \%$ & $56,8 \%$ & $55,0 \%$ & $-14,5 \%$ \\
\hline Cáceres & 35.823 & 8.189 & 27.634 & 12.542 & 6.183 & 6.190 & $35,0 \%$ & $49,4 \%$ & $49,3 \%$ & $-17,8 \%$ \\
\hline Caucasia & 106.887 & 87.225 & 19.662 & 14.452 & 13.716 & 14.734 & $13,5 \%$ & $102,0 \%$ & $94,9 \%$ & $-0,7 \%$ \\
\hline El Bagre & 48.914 & 25.849 & 23.065 & 25.244 & 9.426 & 9.743 & $51,6 \%$ & $38,6 \%$ & $37,3 \%$ & $-32,3 \%$ \\
\hline Nechí & 25.311 & 13.367 & 11.944 & 8.186 & 4.562 & 4.343 & $32,3 \%$ & $53,1 \%$ & $55,7 \%$ & $-14,3 \%$ \\
\hline Tarazá & 40.355 & 24.702 & 15.653 & 21.207 & 12.697 & 12.253 & $52,6 \%$ & $57,8 \%$ & $59,9 \%$ & $-21,1 \%$ \\
\hline Zaragoza & 29.989 & 13.685 & 16.304 & 11.114 & 4.444 & 5.381 & $37,1 \%$ & $48,4 \%$ & $40,0 \%$ & $-22,2 \%$ \\
\hline $\begin{array}{l}\text { MAGDALENA } \\
\text { MEDIO }\end{array}$ & 112.325 & 68.899 & 43.426 & 23.299 & 12.842 & 13.028 & $20,7 \%$ & $55,9 \%$ & $55,1 \%$ & $-9,3 \%$ \\
\hline Caracolí & 4.646 & 2.997 & 1.649 & 538 & 232 & 257 & $11,6 \%$ & $47,8 \%$ & $43,1 \%$ & $-6,6 \%$ \\
\hline Maceo & 7.021 & 2.887 & 4.134 & 1.116 & 524 & 627 & $15,9 \%$ & $56,2 \%$ & $47,0 \%$ & $-8,4 \%$ \\
\hline Puerto Berrío & 45.239 & 40.453 & 4.786 & 5.268 & 1.770 & 2.040 & $11,6 \%$ & $38,7 \%$ & $33,6 \%$ & $-7,7 \%$ \\
\hline Puerto Nare & 18.289 & 7.719 & 10.570 & 1.451 & 2.042 & 1.698 & $7,9 \%$ & $117,0 \%$ & $140,7 \%$ & $3,2 \%$ \\
\hline Puerto Triunfo & 19.263 & 5.894 & 13.369 & 1.161 & 3.722 & 4.360 & $6,0 \%$ & $375,5 \%$ & $320,6 \%$ & $13,3 \%$ \\
\hline Yondó & 17.867 & 8.949 & 8.918 & 13.765 & 4.552 & 4.046 & $77,0 \%$ & $29,4 \%$ & $33,1 \%$ & $-51,6 \%$ \\
\hline NORDESTE & 183.434 & 91.650 & 91.784 & 51.472 & 22.179 & 24.415 & $28,1 \%$ & $47,4 \%$ & $43,1 \%$ & $-16,0 \%$ \\
\hline Amalfi & 21.768 & 11.991 & 9.777 & 4.736 & 2.273 & 2.884 & $21,8 \%$ & $60,9 \%$ & $48,0 \%$ & $-11,3 \%$ \\
\hline Anorí & 16.658 & 6.477 & 10.181 & 11.598 & 5.846 & 5.708 & $69,6 \%$ & $49,2 \%$ & $50,4 \%$ & $-34,5 \%$ \\
\hline Cisneros & 9.191 & 7.640 & 1.551 & 554 & 546 & 620 & $6,0 \%$ & $111,9 \%$ & $98,6 \%$ & $-0,1 \%$ \\
\hline Remedios & 27.832 & 10.123 & 17.709 & 7.708 & 2.549 & 3.331 & $27,7 \%$ & $43,2 \%$ & $33,1 \%$ & $-18,5 \%$ \\
\hline San Roque & 17.077 & 6.250 & 10.827 & 5.225 & 3.477 & 4.119 & $30,6 \%$ & $78,8 \%$ & $66,5 \%$ & $-10,2 \%$ \\
\hline Santo Domingo & 10.650 & 2.026 & 8.624 & 3.038 & 1.373 & 1.561 & $28,5 \%$ & $51,4 \%$ & $45,2 \%$ & $-15,6 \%$ \\
\hline Segovia & 39.163 & 31.183 & 7.980 & 9.261 & 3.268 & 2.415 & $23,6 \%$ & $26,1 \%$ & $35,3 \%$ & $-15,3 \%$ \\
\hline Vegachí & 9.786 & 5.841 & 3.945 & 3.716 & 1.176 & 1.571 & $38,0 \%$ & $42,3 \%$ & $31,6 \%$ & $-26,0 \%$ \\
\hline Yalí & 8.167 & 3.126 & 5.041 & 1.381 & 236 & 267 & $16,9 \%$ & $19,3 \%$ & $17,1 \%$ & $-14,0 \%$ \\
\hline
\end{tabular}




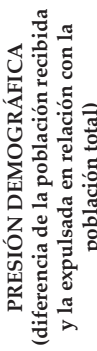

\begin{tabular}{|c|c|c|c|c|c|c|c|c|c|c|}
\hline Yolombó & 23.142 & 6.993 & 16.149 & 4.255 & 1.435 & 1.939 & $18,4 \%$ & $45,6 \%$ & $33,7 \%$ & $-12,2 \%$ \\
\hline NORTE & 254.562 & 117.704 & 136.858 & 63.599 & 34.523 & 33.195 & $25,0 \%$ & $52,2 \%$ & $54,3 \%$ & $-11,4 \%$ \\
\hline Angostura & 11.579 & 1.872 & 9.707 & 2.772 & 1.515 & 1.742 & $23,9 \%$ & $62,8 \%$ & $54,7 \%$ & $-10,9 \%$ \\
\hline Belmira & 6.645 & 1.879 & 4.766 & 375 & 233 & 244 & $5,6 \%$ & $65,1 \%$ & $62,1 \%$ & $-2,1 \%$ \\
\hline Briceño & 8.720 & 2.493 & 6.227 & 4.733 & 1.769 & 1.811 & $54,3 \%$ & $38,3 \%$ & $37,4 \%$ & $-34,0 \%$ \\
\hline Campamento & 9.209 & 2.827 & 6.382 & 2.015 & 348 & 386 & $21,9 \%$ & $19,2 \%$ & $17,3 \%$ & $-18,1 \%$ \\
\hline Carolina del Príncipe & 3.696 & 2.952 & 744 & 229 & 254 & 171 & $6,2 \%$ & $74,7 \%$ & $110,9 \%$ & $0,7 \%$ \\
\hline Donmatías & 21.295 & 13.968 & 7.327 & 331 & 1.455 & 1.424 & $1,6 \%$ & $430,2 \%$ & $439,6 \%$ & $5,3 \%$ \\
\hline Entrerríos & 9.654 & 4.947 & 4.707 & 125 & 182 & 130 & $1,3 \%$ & $104,0 \%$ & $145,6 \%$ & $0,6 \%$ \\
\hline Gómez Plata & 12.513 & 5.769 & 6.744 & 482 & 244 & 262 & $3,9 \%$ & $54,4 \%$ & $50,6 \%$ & $-1,9 \%$ \\
\hline Guadalupe & 6.287 & 2.071 & 4.216 & 849 & 214 & 238 & $13,5 \%$ & $28,0 \%$ & $25,2 \%$ & $-10,1 \%$ \\
\hline Ituango & 21.757 & 5.866 & 15.891 & 30.869 & 14.845 & 15.713 & $141,9 \%$ & $50,9 \%$ & $48,1 \%$ & $-73,6 \%$ \\
\hline $\begin{array}{c}\text { San Andrés de } \\
\text { Cuerquia }\end{array}$ & 6.449 & 2.510 & 3.939 & 1.927 & 681 & 628 & $29,9 \%$ & $32,6 \%$ & $35,3 \%$ & $-19,3 \%$ \\
\hline $\begin{array}{l}\text { San José de La } \\
\text { Montaña }\end{array}$ & 3.277 & 2.168 & 1.109 & 522 & 119 & 137 & $15,9 \%$ & $26,2 \%$ & $22,8 \%$ & $-12,3 \%$ \\
\hline $\begin{array}{c}\text { San Pedro de los } \\
\text { Milagros }\end{array}$ & 25.676 & 13.474 & 12.202 & 3.604 & 1.373 & 1.137 & $14,0 \%$ & $31,5 \%$ & $38,1 \%$ & $-8,7 \%$ \\
\hline Santa Rosa de Osos & 34.753 & 17.902 & 16.851 & 1.463 & 1.055 & 849 & $4,2 \%$ & $58,0 \%$ & $72,1 \%$ & $-1,2 \%$ \\
\hline Toledo & 6.220 & 1.062 & 5.158 & 2.546 & 1.228 & 1.249 & $40,9 \%$ & $49,1 \%$ & $48,2 \%$ & $-21,2 \%$ \\
\hline Valdivia & 21.092 & 6.201 & 14.891 & 5.994 & 4.940 & 2.667 & $28,4 \%$ & $44,5 \%$ & $82,4 \%$ & $-5,0 \%$ \\
\hline Yarumal & 45.740 & 29.743 & 15.997 & 4.763 & 4.068 & 4.407 & $10,4 \%$ & $92,5 \%$ & $85,4 \%$ & $-1,5 \%$ \\
\hline OCCIDENTE & 200.104 & 70.986 & 129.118 & 88.467 & 45.955 & 54.545 & $44,2 \%$ & $61,7 \%$ & $51,9 \%$ & $-21,2 \%$ \\
\hline Abriaquí & 2.231 & 776 & 1.455 & 705 & 546 & 418 & $31,6 \%$ & $59,3 \%$ & $77,4 \%$ & $-7,1 \%$ \\
\hline Anzá & 7.543 & 1.244 & 6.299 & 3.136 & 2.219 & 2.355 & $41,6 \%$ & $75,1 \%$ & $70,8 \%$ & $-12,2 \%$ \\
\hline Armenia & 4.383 & 1.615 & 2.768 & 354 & 160 & 93 & $8,1 \%$ & $26,3 \%$ & $45,2 \%$ & $-4,4 \%$ \\
\hline Buriticá & 6.689 & 1.523 & 5.166 & 5.322 & 3.626 & 3.689 & $79,6 \%$ & $69,3 \%$ & $68,1 \%$ & $-25,4 \%$ \\
\hline Caicedo & 8.099 & 1.599 & 6.500 & 1.975 & 468 & 341 & $24,4 \%$ & $17,3 \%$ & $23,7 \%$ & $-18,6 \%$ \\
\hline Cañasgordas & 16.780 & 6.336 & 10.444 & 5.685 & 1.523 & 2.617 & $33,9 \%$ & $46,0 \%$ & $26,8 \%$ & $-24,8 \%$ \\
\hline Dabeiba & 23.560 & 8.869 & 14.691 & 29.458 & 10.971 & 12.729 & $125,0 \%$ & $43,2 \%$ & $37,2 \%$ & $-78,5 \%$ \\
\hline
\end{tabular}




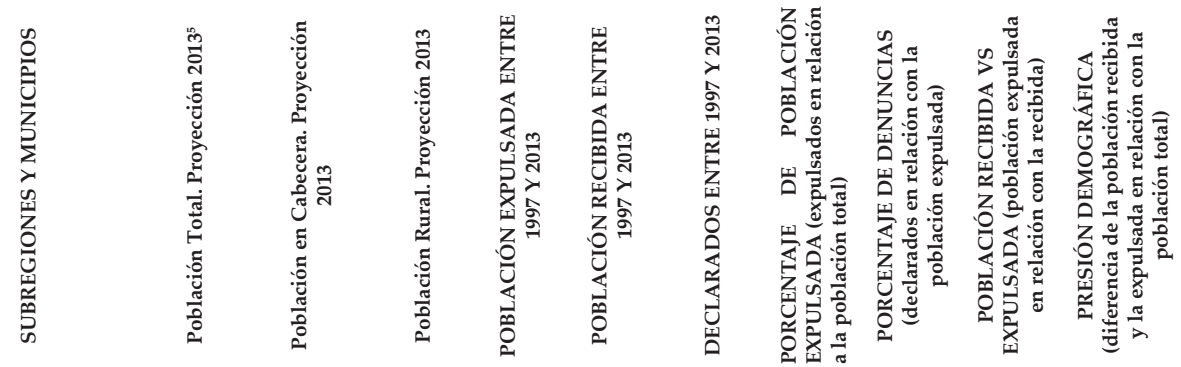

\begin{tabular}{|c|c|c|c|c|c|c|c|c|c|c|}
\hline Ebéjico & 12.526 & 2.201 & 10.325 & 515 & 133 & 58 & $4,1 \%$ & $11,3 \%$ & $25,8 \%$ & $-3,0 \%$ \\
\hline Frontino & 17.261 & 7.106 & 10.155 & 10.565 & 6.621 & 9.148 & $61,2 \%$ & $86,6 \%$ & $62,7 \%$ & $-22,8 \%$ \\
\hline Giraldo & 4.064 & 1.294 & 2.770 & 353 & 180 & 147 & $8,7 \%$ & $41,6 \%$ & $51,0 \%$ & $-4,3 \%$ \\
\hline Heliconia & 6.060 & 3.011 & 3.049 & 1.482 & 565 & 800 & $24,5 \%$ & $54,0 \%$ & $38,1 \%$ & $-15,1 \%$ \\
\hline Liborina & 9.515 & 1.774 & 7.741 & 3.207 & 1.949 & 2.657 & $33,7 \%$ & $82,9 \%$ & $60,8 \%$ & $-13,2 \%$ \\
\hline Olaya & 3.169 & 271 & 2.898 & 242 & 41 & 97 & $7,6 \%$ & $40,1 \%$ & $16,9 \%$ & $-6,3 \%$ \\
\hline Peque & 10.669 & 1.955 & 8.714 & 13.523 & 9.221 & 10.031 & $126,8 \%$ & $74,2 \%$ & $68,2 \%$ & $-40,3 \%$ \\
\hline Sabanalarga & 8.191 & 2.859 & 5.332 & 3.244 & 2.297 & 2.780 & $39,6 \%$ & $85,7 \%$ & $70,8 \%$ & $-11,6 \%$ \\
\hline San Jerónimo & 12.456 & 3.979 & 8.477 & 574 & 382 & 370 & $4,6 \%$ & $64,5 \%$ & $66,6 \%$ & $-1,5 \%$ \\
\hline Santa Fe de Antioquia & 24.202 & 15.253 & 8.949 & 2.055 & 1.224 & 1.375 & $8,5 \%$ & $66,9 \%$ & $59,6 \%$ & $-3,4 \%$ \\
\hline Sopetrán & 14.453 & 6.757 & 7.696 & 728 & 542 & 659 & $5,0 \%$ & $90,5 \%$ & $74,5 \%$ & $-1,3 \%$ \\
\hline Uramita & 8.253 & 2.564 & 5.689 & 5.344 & 3.287 & 4.181 & $64,8 \%$ & $78,2 \%$ & $61,5 \%$ & $-24,9 \%$ \\
\hline ORIENTE & 573.885 & 326.278 & 247.607 & 236.356 & 147.955 & 164.673 & $41,2 \%$ & $69,7 \%$ & $62,6 \%$ & $-15,4 \%$ \\
\hline Abejorral & 19.478 & 6.587 & 12.891 & 7.518 & 3.177 & 3.537 & $38,6 \%$ & $47,0 \%$ & $42,3 \%$ & $-22,3 \%$ \\
\hline Alejandría & 3.550 & 1.824 & 1.726 & 4.637 & 2.970 & 3.127 & $130,6 \%$ & $67,4 \%$ & $64,1 \%$ & $-47,0 \%$ \\
\hline Argelia & 8.968 & 2.622 & 6.346 & 19.534 & 11.713 & 13.096 & $217,8 \%$ & $67,0 \%$ & $60,0 \%$ & $-87,2 \%$ \\
\hline Cocorná & 15.010 & 3.966 & 11.044 & 26.161 & 13.372 & 15.593 & $174,3 \%$ & $59,6 \%$ & $51,1 \%$ & $-85,2 \%$ \\
\hline Concepción & 3.659 & 1.437 & 2.222 & 2.244 & 1.045 & 1.103 & $61,3 \%$ & $49,2 \%$ & $46,6 \%$ & $-32,8 \%$ \\
\hline El Carmen de Viboral & 45.578 & 28.576 & 17.002 & 6.528 & 5.169 & 4.657 & $14,3 \%$ & $71,3 \%$ & $79,2 \%$ & $-3,0 \%$ \\
\hline El Peñol & 15.985 & 9.020 & 6.965 & 3.904 & 2.504 & 2.670 & $24,4 \%$ & $68,4 \%$ & $64,1 \%$ & $-8,8 \%$ \\
\hline El Retiro & 18.712 & 9.618 & 9.094 & 393 & 1.050 & 942 & $2,1 \%$ & $239,7 \%$ & $267,2 \%$ & $3,5 \%$ \\
\hline El Santuario & 26.981 & 22.473 & 4.508 & 3.434 & 6.578 & 6.282 & $12,7 \%$ & $182,9 \%$ & $191,6 \%$ & $11,7 \%$ \\
\hline Granada & 9.838 & 3.699 & 6.139 & 23.293 & 8.338 & 10.470 & $236,8 \%$ & $44,9 \%$ & $35,8 \%$ & $-152,0 \%$ \\
\hline Guarne & 46.096 & 16.791 & 29.305 & 794 & 2.153 & 2.175 & $1,7 \%$ & $273,9 \%$ & $271,2 \%$ & $2,9 \%$ \\
\hline Guatapé & 5.394 & 4.174 & 1.220 & 684 & 511 & 313 & $12,7 \%$ & $45,8 \%$ & $74,7 \%$ & $-3,2 \%$ \\
\hline La Ceja del Tambo & 51.445 & 44.399 & 7.046 & 1.061 & 4.212 & 3.826 & $2,1 \%$ & $360,6 \%$ & $397,0 \%$ & $6,1 \%$ \\
\hline La Unión & 18.905 & 10.492 & 8.413 & 5.458 & 6.408 & 7.987 & $28,9 \%$ & $146,3 \%$ & $117,4 \%$ & $5,0 \%$ \\
\hline
\end{tabular}




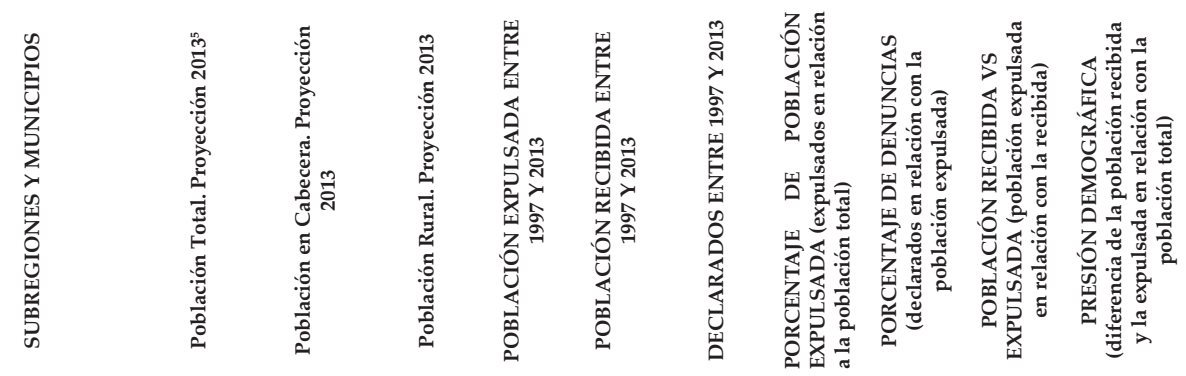

\begin{tabular}{|c|c|c|c|c|c|c|c|c|c|c|}
\hline Marinilla & 51.767 & 40.083 & 11.684 & 2.730 & 6.917 & 6.834 & $5,3 \%$ & $250,3 \%$ & $253,4 \%$ & $8,1 \%$ \\
\hline Nariño & 16.913 & 2.508 & 14.405 & 13.929 & 4.976 & 6.807 & $82,4 \%$ & $48,9 \%$ & $35,7 \%$ & $-52,9 \%$ \\
\hline Rionegro & 116.289 & 76.006 & 40.283 & 1.149 & 10.897 & 10.570 & $1,0 \%$ & $919,9 \%$ & $948,4 \%$ & $8,4 \%$ \\
\hline San Carlos & 16.008 & 6.053 & 9.955 & 30.434 & 9.955 & 11.388 & $190,1 \%$ & $37,4 \%$ & $32,7 \%$ & $-127,9 \%$ \\
\hline San Francisco & 5.521 & 2.427 & 3.094 & 15.538 & 6.533 & 7.772 & $281,4 \%$ & $50,0 \%$ & $42,0 \%$ & $-163,1 \%$ \\
\hline San Luis & 10.956 & 4.692 & 6.264 & 24.723 & 16.038 & 17.655 & $225,7 \%$ & $71,4 \%$ & $64,9 \%$ & $-79,3 \%$ \\
\hline San Rafael & 13.076 & 6.279 & 6.797 & 20.066 & 10.790 & 13.943 & $153,5 \%$ & $69,5 \%$ & $53,8 \%$ & $-70,9 \%$ \\
\hline San Vicente Ferrer & 17.652 & 7.331 & 10.321 & 4.807 & 2.155 & 3.461 & $27,2 \%$ & $72,0 \%$ & $44,8 \%$ & $-15,0 \%$ \\
\hline Sonsón & 36.104 & 15.221 & 20.883 & 17.337 & 10.494 & 10.465 & $48,0 \%$ & $60,4 \%$ & $60,5 \%$ & $-19,0 \%$ \\
\hline SUROESTE & 376.422 & 183.504 & 192.918 & 74.733 & 39.889 & 46.752 & $19,9 \%$ & $62,6 \%$ & $53,4 \%$ & $-9,3 \%$ \\
\hline Amagá & 29.117 & 16.312 & 12.805 & 1.116 & 680 & 577 & $3,8 \%$ & $51,7 \%$ & $60,9 \%$ & $-1,5 \%$ \\
\hline Andes & 44.994 & 21.972 & 23.022 & 2.545 & 1.603 & 1.367 & $5,7 \%$ & $53,7 \%$ & $63,0 \%$ & $-2,1 \%$ \\
\hline Angelópolis & 8.680 & 5.115 & 3.565 & 1.237 & 567 & 778 & $14,3 \%$ & $62,9 \%$ & $45,8 \%$ & $-7,7 \%$ \\
\hline Betania & 9.487 & 3.853 & 5.634 & 1.360 & 829 & 1.142 & $14,3 \%$ & $84,0 \%$ & $61,0 \%$ & $-5,6 \%$ \\
\hline Betulia & 17.409 & 5.709 & 11.700 & 15.888 & 9.738 & 10.931 & $91,3 \%$ & $68,8 \%$ & $61,3 \%$ & $-35,3 \%$ \\
\hline Caramanta & 5.395 & 2.880 & 2.515 & 376 & 121 & 129 & $7,0 \%$ & $34,3 \%$ & $32,2 \%$ & $-4,7 \%$ \\
\hline Ciudad Bolívar & 27.335 & 16.225 & 11.110 & 2.632 & 1.310 & 1.285 & $9,6 \%$ & $48,8 \%$ & $49,8 \%$ & $-4,8 \%$ \\
\hline Concordia & 20.843 & 8.544 & 12.299 & 2.644 & 766 & 1.018 & $12,7 \%$ & $38,5 \%$ & $29,0 \%$ & $-9,0 \%$ \\
\hline Fredonia & 21.817 & 8.585 & 13.232 & 405 & 480 & 402 & $1,9 \%$ & $99,3 \%$ & $118,5 \%$ & $0,3 \%$ \\
\hline Hispania & 4.859 & 3.199 & 1.660 & 125 & 133 & 96 & $2,6 \%$ & $76,8 \%$ & $106,4 \%$ & $0,2 \%$ \\
\hline Jardín & 13.900 & 7.172 & 6.728 & 724 & 355 & 375 & $5,2 \%$ & $51,8 \%$ & $49,0 \%$ & $-2,7 \%$ \\
\hline Jericó & 12.249 & 8.339 & 3.910 & 185 & 180 & 224 & $1,5 \%$ & $121,1 \%$ & $97,3 \%$ & $0,0 \%$ \\
\hline La Pintada & 6.665 & 5.786 & 879 & 597 & 272 & 110 & $9,0 \%$ & $18,4 \%$ & $45,6 \%$ & $-4,9 \%$ \\
\hline Montebello & 6.450 & 2.009 & 4.441 & 3.361 & 1.203 & 1.220 & $52,1 \%$ & $36,3 \%$ & $35,8 \%$ & $-33,5 \%$ \\
\hline Pueblorrico & 7.272 & 3.717 & 3.555 & 916 & 172 & 256 & $12,6 \%$ & $27,9 \%$ & $18,8 \%$ & $-10,2 \%$ \\
\hline Salgar & 17.740 & 8.663 & 9.077 & 4.952 & 1.320 & 1.362 & $27,9 \%$ & $27,5 \%$ & $26,7 \%$ & $-20,5 \%$ \\
\hline Santa Bárbara & 22.397 & 10.382 & 12.015 & 2.190 & 1.913 & 1.821 & $9,8 \%$ & $83,2 \%$ & $87,4 \%$ & $-1,2 \%$ \\
\hline
\end{tabular}




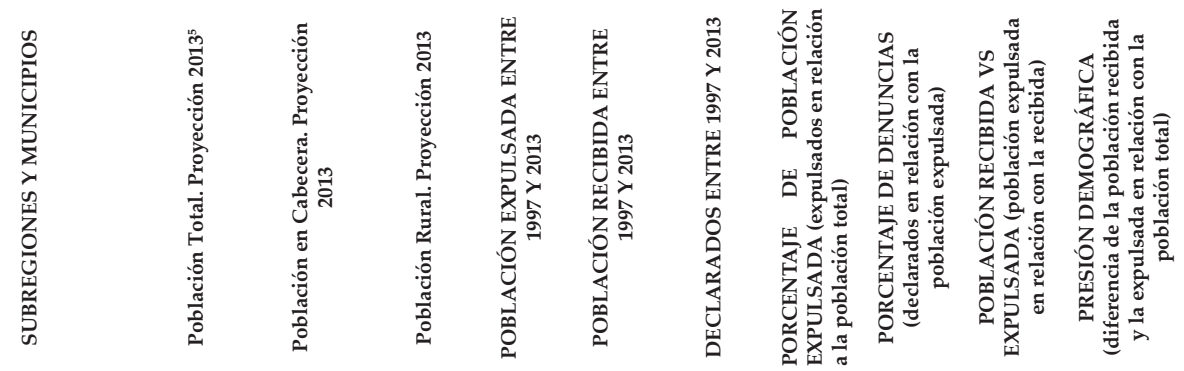

\begin{tabular}{|c|c|c|c|c|c|c|c|c|c|c|}
\hline Támesis & 15.058 & 6.492 & 8.566 & 1.113 & 334 & 371 & $7,4 \%$ & $33,3 \%$ & $30,0 \%$ & $-5,2 \%$ \\
\hline Tarso & 7.616 & 3.675 & 3.941 & 273 & 64 & 57 & $3,6 \%$ & $20,9 \%$ & $23,4 \%$ & $-2,7 \%$ \\
\hline Titiribí & 14.199 & 7.849 & 6.350 & 349 & 176 & 159 & $2,5 \%$ & $45,6 \%$ & $50,4 \%$ & $-1,2 \%$ \\
\hline Urrao & 43.436 & 16.922 & 26.514 & 30.953 & 17.161 & 22.443 & $71,3 \%$ & $72,5 \%$ & $55,4 \%$ & $-31,8 \%$ \\
\hline Valparaíso & 6.209 & 3.370 & 2.839 & 261 & 165 & 253 & $4,2 \%$ & $96,9 \%$ & $63,2 \%$ & $-1,5 \%$ \\
\hline Venecia & 13.295 & 6.734 & 6.561 & 531 & 347 & 376 & $4,0 \%$ & $70,8 \%$ & $65,3 \%$ & $-1,4 \%$ \\
\hline URABÁ & 626.597 & 368.157 & 258.440 & 218.133 & 230.159 & 337.141 & $34,8 \%$ & $154,6 \%$ & $105,5 \%$ & $1,9 \%$ \\
\hline Apartadó & 167.895 & 144.976 & 22.919 & 41.813 & 53.123 & 94.149 & $24,9 \%$ & $225,2 \%$ & $127,0 \%$ & $6,7 \%$ \\
\hline Arboletes & 38.100 & 15.887 & 22.213 & 8.958 & 5.099 & 16.444 & $23,5 \%$ & $183,6 \%$ & $56,9 \%$ & $-10,1 \%$ \\
\hline Carepa & 53.048 & 40.020 & 13.028 & 10.405 & 20.971 & 27.001 & $19,6 \%$ & $259,5 \%$ & $201,5 \%$ & $19,9 \%$ \\
\hline Chigorodó & 72.453 & 62.927 & 9.526 & 17.533 & 26.648 & 33.140 & $24,2 \%$ & $189,0 \%$ & $152,0 \%$ & $12,6 \%$ \\
\hline Murindó & 4.402 & 982 & 3.420 & 2.545 & 3.846 & 4.669 & $57,8 \%$ & $183,5 \%$ & $151,1 \%$ & $29,6 \%$ \\
\hline Mutatá & 19.714 & 5.273 & 14.441 & 31.265 & 22.992 & 28.484 & $158,6 \%$ & $91,1 \%$ & $73,5 \%$ & $-42,0 \%$ \\
\hline Necoclí & 59.230 & 14.572 & 44.658 & 13.471 & 7.250 & 28.449 & $22,7 \%$ & $211,2 \%$ & $53,8 \%$ & $-10,5 \%$ \\
\hline San Juan de Urabá & 24.253 & 7.742 & 16.511 & 7.792 & 6.930 & 11.227 & $32,1 \%$ & $144,1 \%$ & $88,9 \%$ & $-3,6 \%$ \\
\hline San Pedro de Urabá & 30.785 & 13.648 & 17.137 & 12.922 & 10.002 & 20.282 & $42,0 \%$ & $157,0 \%$ & $77,4 \%$ & $-9,5 \%$ \\
\hline Turbo & 151.161 & 60.042 & 91.119 & 59.541 & 70.399 & 66.972 & $39,4 \%$ & $112,5 \%$ & $118,2 \%$ & $7,2 \%$ \\
\hline Vigía del Fuerte & 5.556 & 2.088 & 3.468 & 11.888 & 2.899 & 6.324 & $214,0 \%$ & $53,2 \%$ & $24,4 \%$ & $-161,8 \%$ \\
\hline
\end{tabular}

Fuente: Elaboración propia con base en los registros de la Red Nacional de Información (RNI)

Teniendo en cuenta la información anterior es posible establecer los efectos territoriales del fenómeno. A continuación, se presenta gráficamente los principales municipios con población expulsada en el período de análisis. 


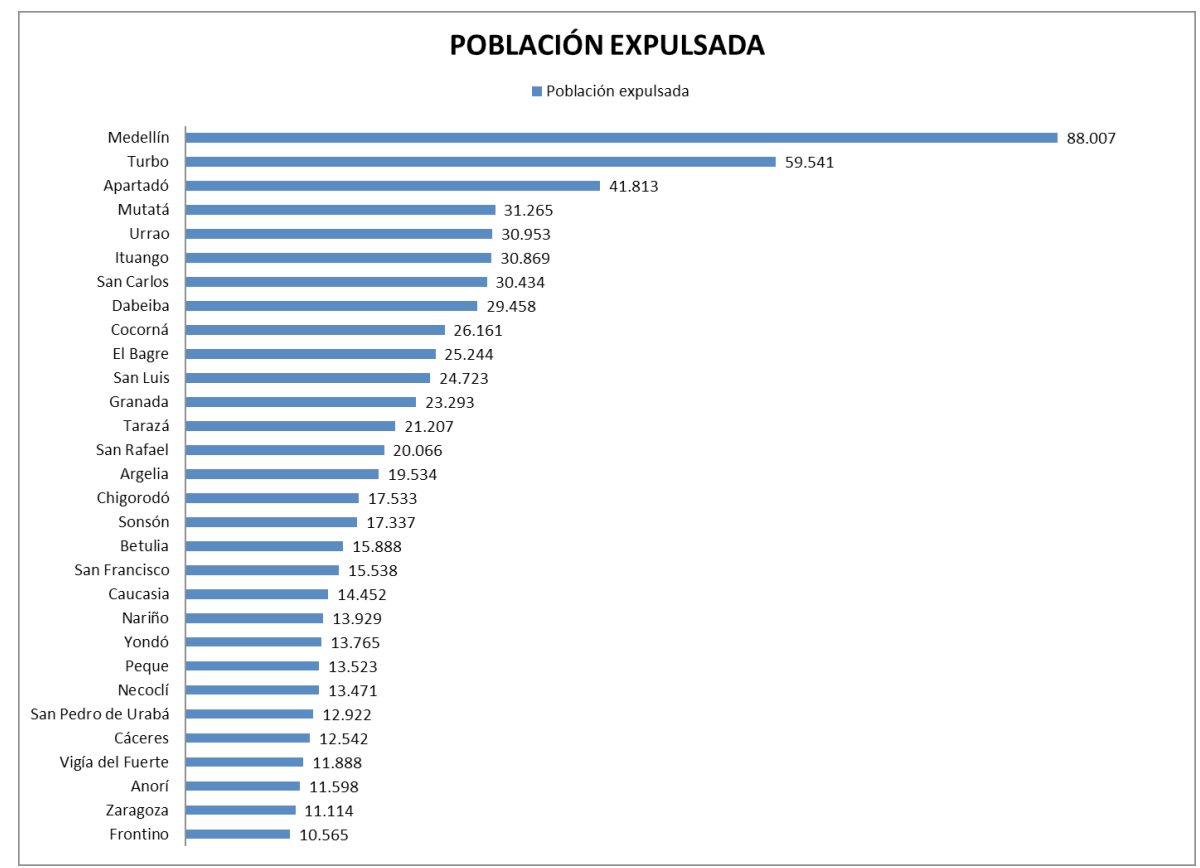

Gráfica 1. Población expulsada por municipio.

Fuente: Elaboración propia con base en los registros de la Red

Nacional de Información (RNI). Datos 1997- 2013

Medellín, como principal expulsor de Antioquia, tiene que ver con condiciones endógenas de violencia, desplazamientos intraurbanos y en la cantidad relativa a la población residente. Es relevante observar la expulsión en los municipios pertenecientes a las subregiones de Oriente y Urabá. Por ejemplo, San Carlos es un municipio rural, cuenta con una población urbana de 6.031 habitantes y rural de $10.033^{7}$, durante el período de estudio se cuenta con registro de la expulsión de 30.434 personas, cifra correspondiente al 190 \% de la población actual. En la misma lógica se inscriben los demás municipios en los que la expulsión constituyó una completa reconfiguración de las dinámicas sociales. Así como la expulsión, la recepción de estas olas migratorias produjo impactos en las ciudades y los centros poblados convirtiendo sus periferias en campamentos de refugiados, rebasando la capacidad institucional de atender las demandas de esta población.

\footnotetext{
${ }^{7}$ Datos extraídos de respuesta a derecho de petición enviado al municipio fechado en abril 18 de 2015 que contiene diversos datos de población: “Proyección 2011 Sisben: 15.951 habitantes. Proyección 2015: 16.034 habitantes".
} 
Gráficamente, se presentan los principales municipios receptores en el período de análisis. Antioquia también es el principal receptor (983.851 personas), observándose presión demográfica en Medellín, el Área Metropolitana y Urabá, calculada como la diferencia entre la población recibida y la población expulsada por número de habitantes.

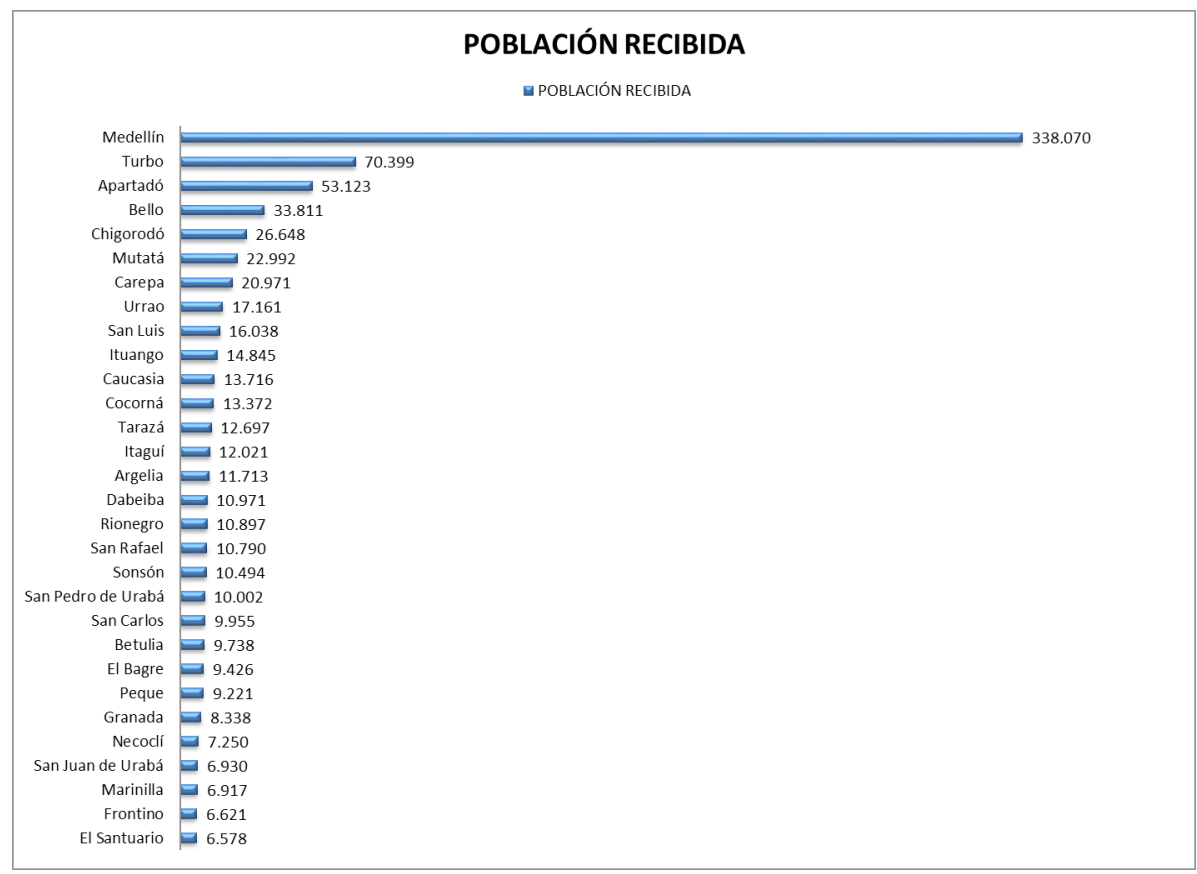

Gráfica 2. Población recibida por municipio.

Fuente: Elaboración propia con base en los registros de la Red Nacional de Información (RNI). Datos 1997-2013

Municipios cómo Medellín, Bello e Itagüí en el Valle de Aburrá fueron receptores en menos de 15 años de una oleada migratoria no correspondiente con sus planes de crecimiento y recursos estatales. 


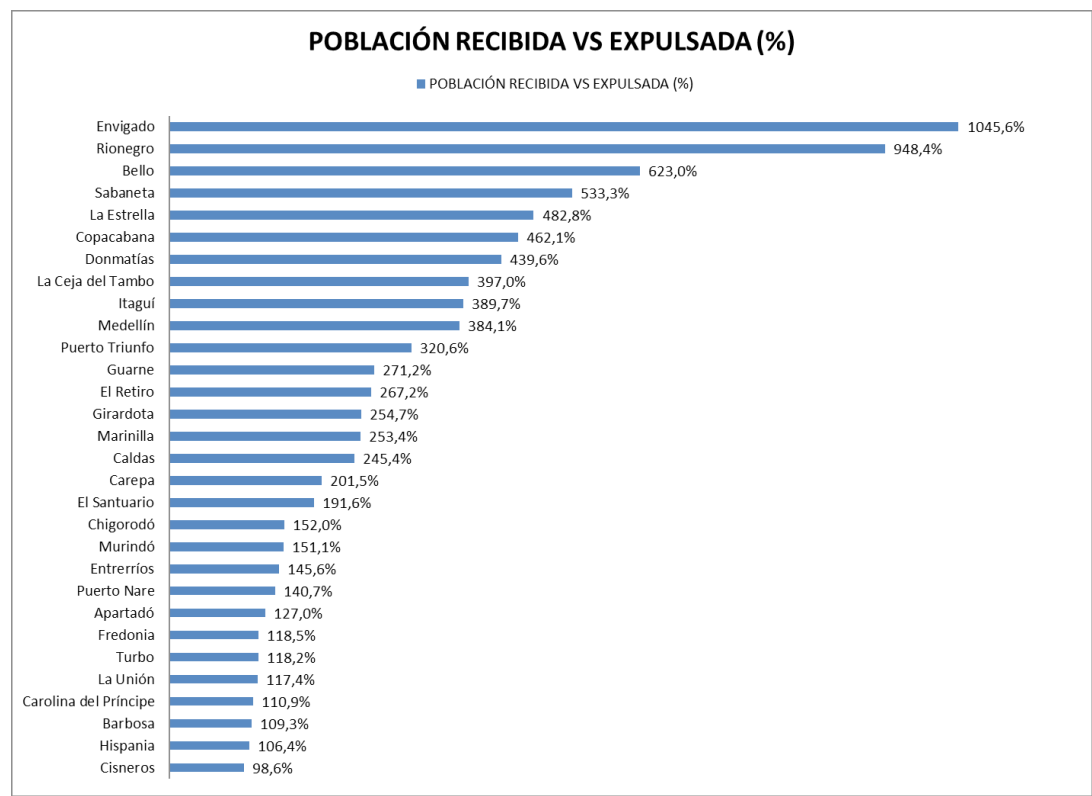

Gráfica 3. Gráfico población recibida versus expulsada.

Fuente: Elaboración propia con base en los registros de la Red Nacional de Información (RNI). Datos 1997-2013

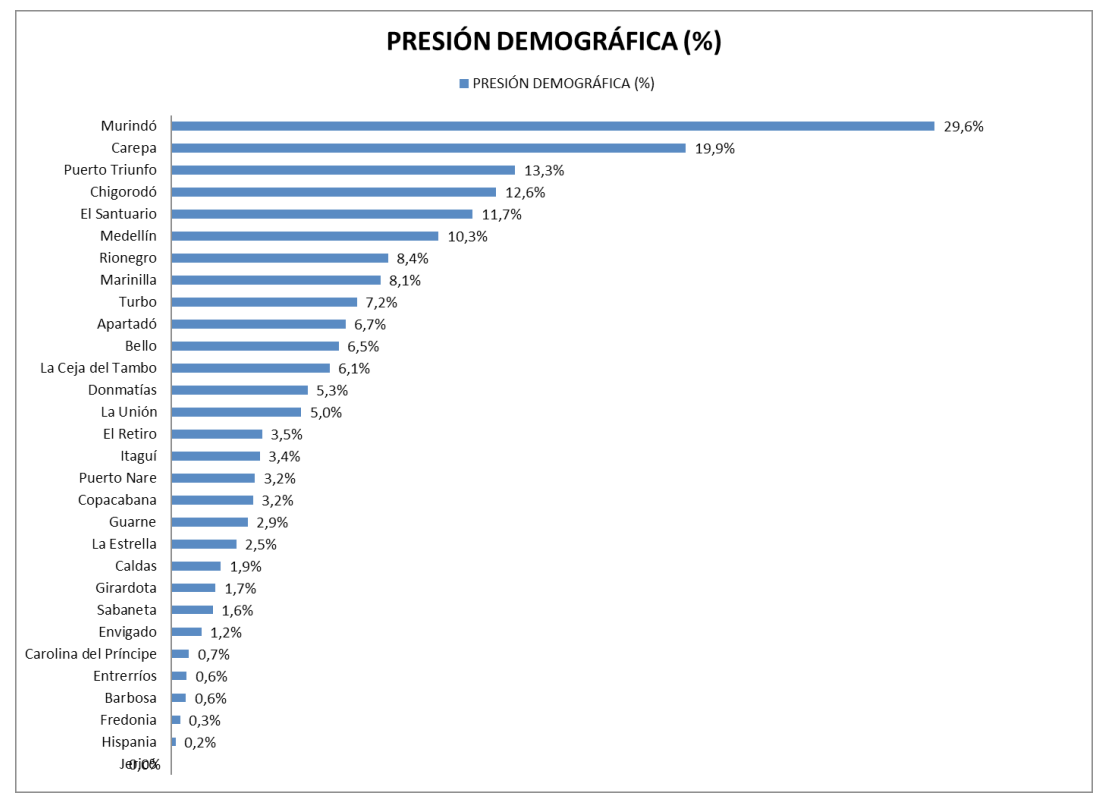

Gráfica 4. Presión demográfica de la población recibida en relación con la población total. Fuente: Elaboración propia con base en los registros de la Red

Nacional de Información (RNI). Datos 1997-2013 
Es significativo que los municipios con los porcentajes más altos no corresponden a expulsores, pues la presión la ejerce la población recibida. En el caso de Turbo y Apartadó que se encuentran en segundo y tercer lugar como expulsores, se explica porque Urabá tiene la mayor presión demográfica por recepción con el Valle de Aburrá.

Murindó está localizado en la subregión de Urabá en una margen del río Atrato, su única vía de comunicación. Fue un municipio rural receptor en una cantidad significativa respecto a los desplazados teniendo en cuenta el número de habitantes; es un municipio de 4.402 habitantes, 982 de los cuales se ubican en su cabecera y el resto en las zonas rurales, con 2.545 expulsados y 3.846 recibidos por las migraciones provenientes del Urabá antioqueño y chocoano a través del Atrato.

En general por subregión, en términos relativos a la población el porcentaje de expulsión fue el siguiente.

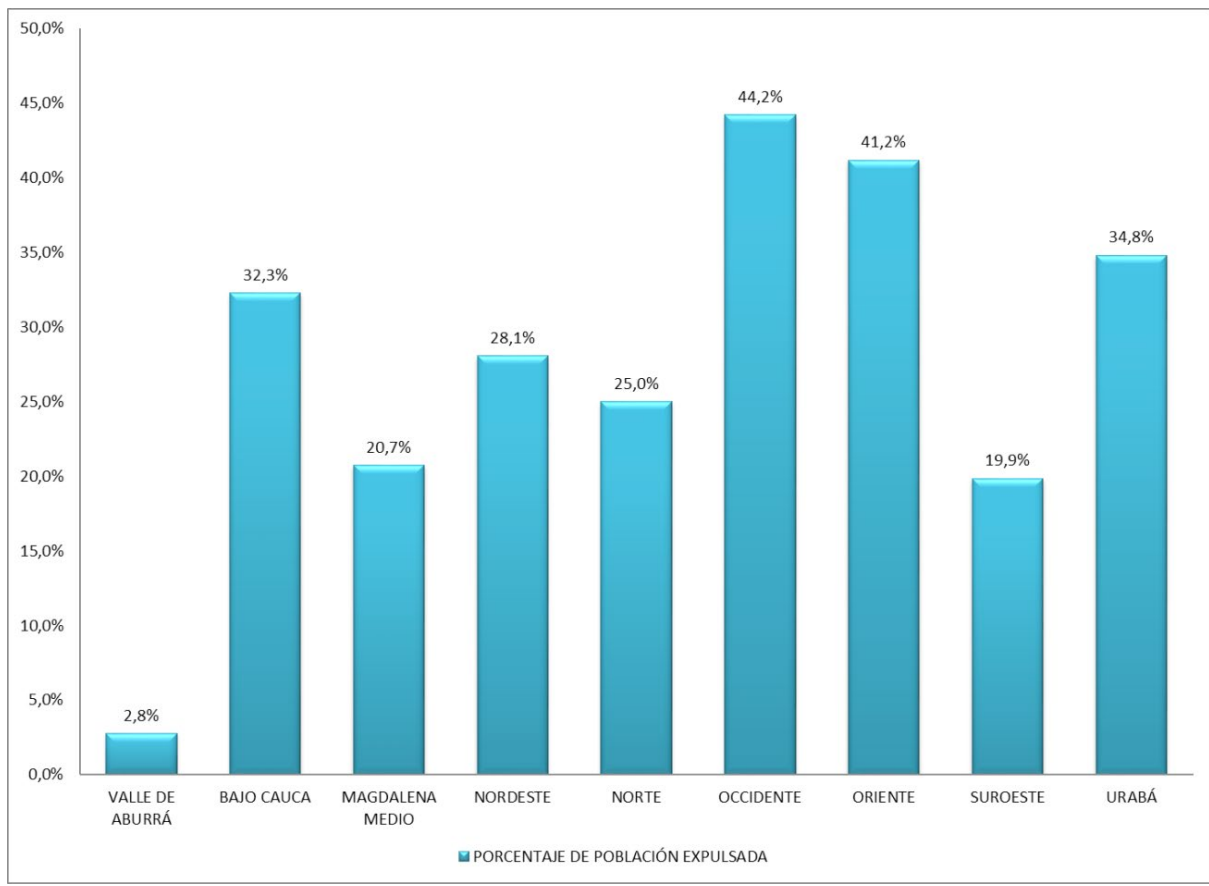

Gráfica 5. Porcentaje de población expulsada por subregión. Fuente: Elaboración propia con base en los registros de la Red Nacional de Información (RNI). Datos 1997-2013 
Aunque relativo al número de habitantes fue la subregión de Occidente la que tuvo el mayor porcentaje de expulsión, en términos absolutos fueron las subregiones de Urabá y Oriente, donde el número de personas desplazadas fue de más de 200 mil en el período.

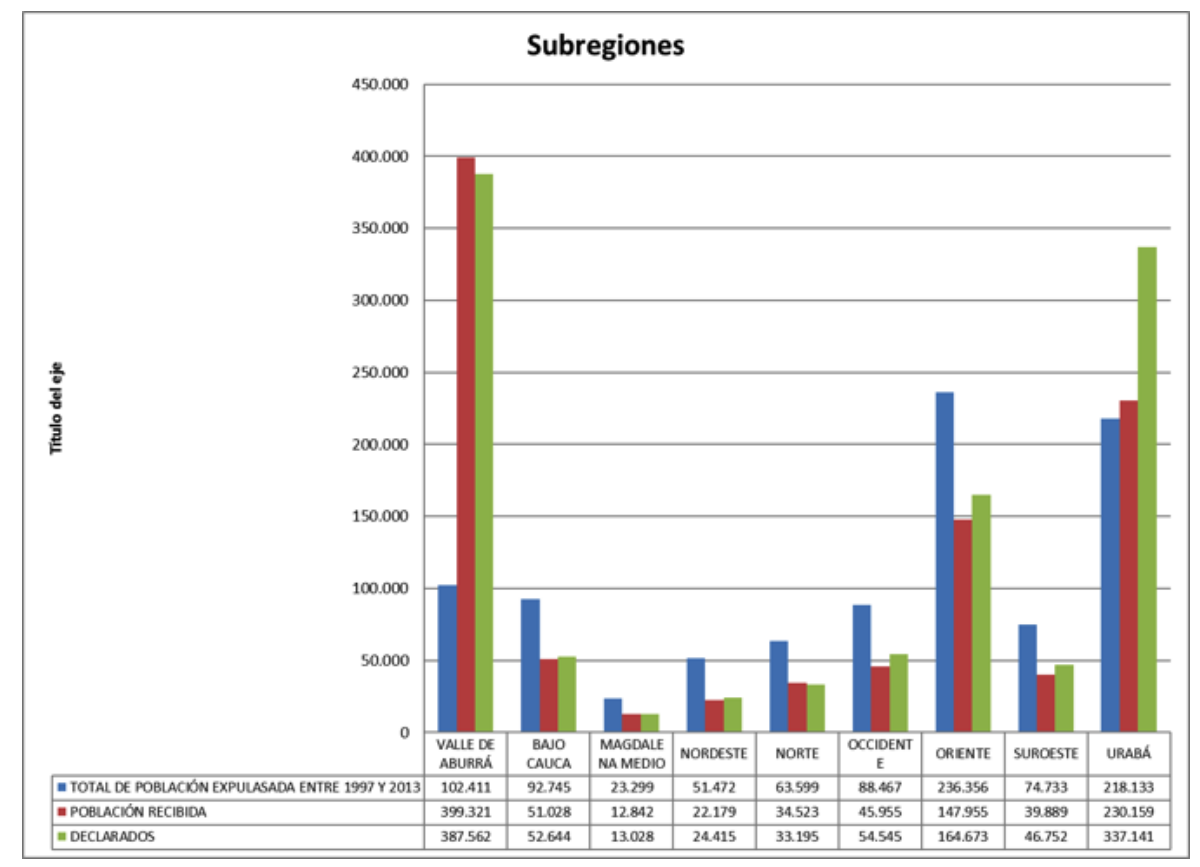

Gráfica 6. El desplazamiento por subregión.

Fuente: Elaboración propia con base en los registros de la Red

Nacional de Información (RNI). Datos 1997-2013

Se destaca Urabá y el Valle de Aburrá en el número de declaraciones. En general, todas las subregiones del departamento tuvieron un impacto demográfico negativo durante el período de estudio a excepción de Urabá y el Valle de Aburrá. 


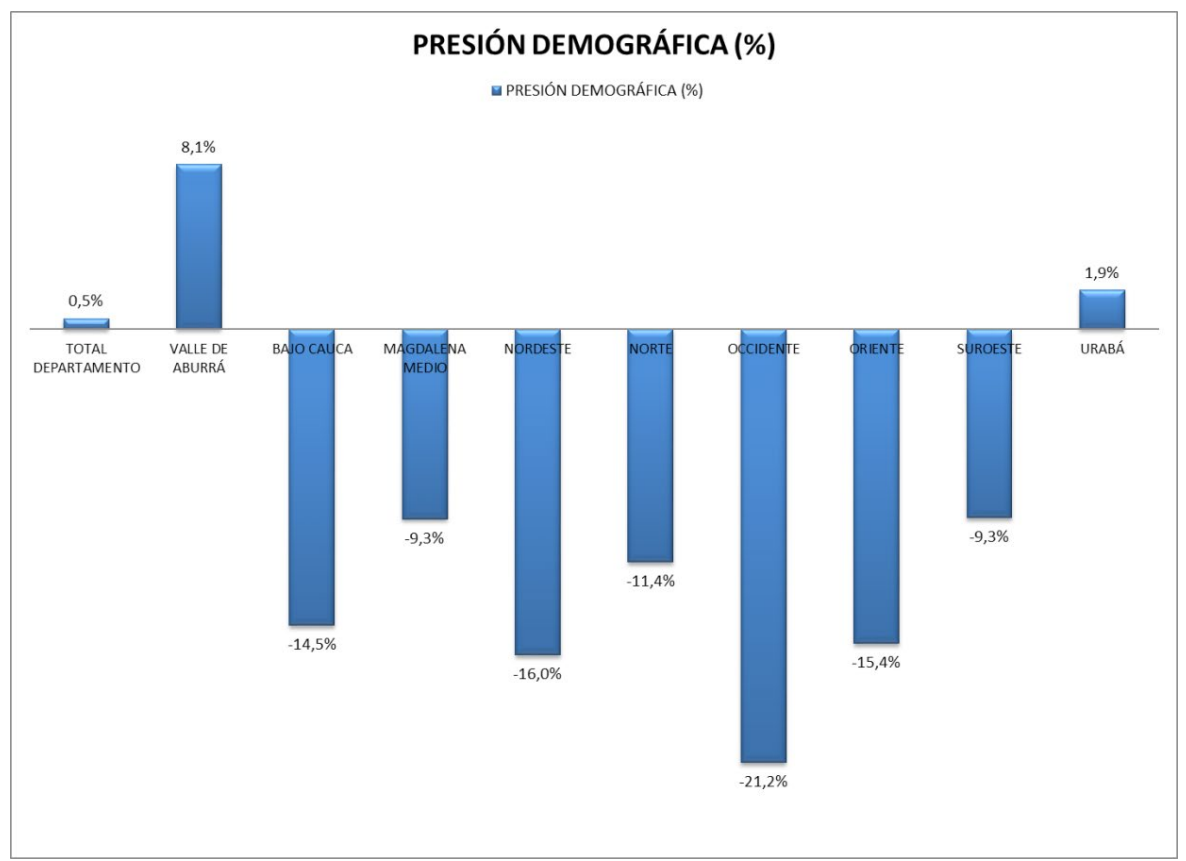

Gráfica 7. Presión demográfica por subregión.

Fuente: Elaboración propia con base en los registros de la Red

Nacional de Información (RNI). Datos 1997-2013

En el Valle de Aburrá se encuentra la capital y reúne los principales municipios del departamento y fue la que tuvo el mayor impacto de las migraciones producidas por desplazamiento forzado, lo que incide en la configuración de la urbanización actual, así como Urabá con un incremento poblacional producto de la recepción.

Las demás subregiones sufrieron un fenómeno de desocupación considerable. Es significativo que más del $80 \%$ de los municipios de estas subregiones son rurales, dicha desocupación condujo a un campo más empobrecido lo que se vio reflejado en el diagnóstico de la ruralidad del Censo Nacional Agropecuario realizado entre 2013 y 2014.

Antioquia es el sexto departamento del país con mayor área rural, con el 5,6\% del total nacional, superado únicamente por departamentos pertenecientes a los antiguos territorios nacionales: Amazonas, Guainía, Caquetá, Vichada y Meta; el departamento, con 8,6 \% tiene la tercera mayor participación de área con uso agropecuario, superado por Meta y Casanare. En el territorio de Antioquia se encuentra el 3,8\% del área de bosques naturales del país, el 7,9\% del área agropecuaria, el 8,7 \% de área no 
agropecuaria y el 6,8 \% del área en otros usos y coberturas de la tierra. Las mayores áreas totales son las de gran tamaño, ante todo en lo que respecta a bosques naturales y áreas agropecuarias (acumulación). Porcentualmente, las áreas de más de 1.000 hectáreas representan el 3\% del total nacional. La sumatoria del territorio antioqueño equivale aproximadamente a 6,26 millones de hectáreas, que representa el 5,6 \% del territorio nacional (DANE, 2015).

Colombia cuenta con un poco más de 7 millones de ha con cultivos que corresponde al 6,3\% del total, mientras en Antioquia el 11,5\% del territorio está cultivado, lo que muestra la vocación agraria del departamento. En el país existe un 2,2\% de la tierra en barbecho ${ }^{8}$, mientras que en Antioquia es sólo el $0,9 \%$, lo anterior puede tener relación con las condiciones propicias del suelo agrícola; se identificaron un poco más de 52 mil productores ${ }^{9}$ en el área censada, de los cuales el $96 \%$ no se identifican como población étnica, y el restante $4 \%$ sí. El 30,7 \% del total de productores residentes son mujeres, y el restante porcentaje hombres y el porcentaje de menores de 40 años es de $28,8 \%$. Lo anterior es significativo frente a la media nacional (Ruiz, Arrubla y Sanabria, 2013). Los indicadores demográficos de Colombia para el año 2015 según el DANE, ${ }^{10}$, establecen que en el país el 49,4\% de la población es masculina ${ }^{11}$ y según edad, el 66,4 \% de ellos es menor de 40 años. Lo anterior indica un envejecimiento significativo de la población de productores rurales respecto a la media demográfica.

El nivel educativo de los productores censados también es muy bajo, la mayoría a nivel departamental (58\% del total), solo cursaron básica primaria o menos. La otra clasificación representativa es *Ninguna, que en Antioquia corresponde al $17 \%$.

Los datos de analfabetismo de los productores residentes son de 16 $\%$ en el país y de $14 \%$ en el departamento. Por sexo, el analfabetismo en Antioquia es $13 \%$ de mujeres y $15 \%$ de hombres productores que no leen ni escriben español.

En cuanto a la seguridad social, el porcentaje de los afiliados al régimen contributivo es de 20,8\%; el $74 \%$ está en el régimen subsidiado y el 2,7 \% no se encuentra afiliado a ningún régimen. El 94,4\% de las UPA

\footnotetext{
${ }^{8}$ Tierra sin cultivar con el fin de recuperarla y dejarla descansar para que recupere propiedades para la próxima cosecha.

${ }^{9}$ El informe de la segunda entrega definitiva del censo define productor como: "la persona natural o jurídica que dirige la UPA y toma las principales decisiones sobre el cultivo de las plantas, la cría de animales, las prácticas agropecuarias, el uso sobre los medios de producción y la venta de los productos agropecuarios" (DANE, 2015, pág. 4. 2da entrega).

${ }^{10}$ Departamento Nacional de Estadística.

${ }^{11}$ Conciliación Censal 1985-2015 e Indicadores demográficos 1985-2020 (DANE).
} 
(unidades de producción agropecuaria) se encuentran en territorios no étnicos, a la vez que el 93,7 \% de los productores. Lo anterior dado que en el departamento habitan pocas comunidades, sus derechos de propiedad colectiva no son extensos como en otras regiones del país y las personas pertenecientes a minorías étnicas no son productoras.

En cuanto a las características de habitación, se presentan las siguientes características.

Tabla 7. Total viviendas ocupadas con personas presentes, desocupadas y de uso temporal, para el total en el área rural dispersa censada

\begin{tabular}{lrrrr}
\hline & \multicolumn{4}{c}{ Total área rural dispersa censada } \\
\cline { 2 - 5 } DOMINIO & Total viviendas & \multicolumn{2}{c}{ Condición de ocupación de la vivienda } \\
\cline { 3 - 5 } & 2.053 .804 & $\begin{array}{c}\text { Ocupadas con personas } \\
\text { presentes }\end{array}$ & De uso temporal & Desocupada \\
\hline Total Nacional & 259.090 & 1.495 .843 & 191.778 & 366.183 \\
\hline Antioquia & & 175.851 & 34.161 & 49.078 \\
\hline
\end{tabular}

Fuente: Datos del Censo Nacional Agropecuario, Anexo 3, tercera entrega

De un poco más de 250 mil viviendas en el área rural en Antioquia $67,8 \%$ de ellas están ocupadas, $13 \%$ con ocupación temporal y 18,9\% desocupadas. Son números muy significativos ya que en Antioquia el déficit de vivienda se estima en 110 mil unidades (Zuluaga, 2016), 70 \% de él para familias pobres, es decir 77 mil; de manera que la vivienda desocupada en las zonas rurales corresponde al 63,6\% del déficit de vivienda departamental para familias de escasos recursos. En Antioquia el $76 \%$ de las viviendas ocupadas se encuentran en las áreas de producción agropecuaria.

Tabla 8. Número de hogares y promedio de hogares por vivienda para el total en el área rural dispersa censada

\begin{tabular}{|c|c|c|c|c|c|c|c|c|c|}
\hline \multirow[b]{2}{*}{ Dominio } & \multicolumn{3}{|c|}{$\begin{array}{c}\text { Total área rural dispersa } \\
\text { censada }\end{array}$} & \multicolumn{3}{|c|}{$\begin{array}{c}\text { Total área rural dispersa } \\
\text { censada en territorios de } \\
\text { grupos étnicos }\end{array}$} & \multicolumn{3}{|c|}{$\begin{array}{c}\text { Total área rural dispersa } \\
\text { censada sin territorios de } \\
\text { grupos étnicos }\end{array}$} \\
\hline & 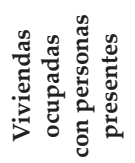 & 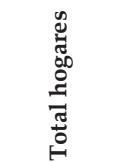 & 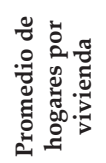 & 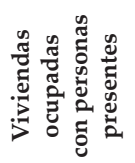 & 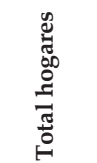 & 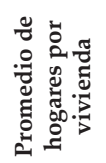 & 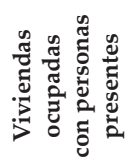 & 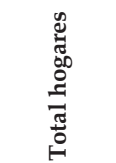 & 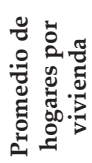 \\
\hline $\begin{array}{c}\text { Total } \\
\text { Nacional }\end{array}$ & 1.495 .843 & 1.543 .134 & 1,032 & 248.702 & 255.336 & 1,027 & 1.247 .141 & 1.287 .798 & 1,033 \\
\hline Antioquia & 175.851 & 180.819 & 1,028 & 4.684 & 4.788 & 1,022 & 171.167 & 176.031 & 1,028 \\
\hline
\end{tabular}

Datos del Censo Nacional Agropecuario, Anexo 3, tercera entrega

118 | antropol.sociol. Vol. 20 No. 2, julio - diciembre 2018, págs. 95-124 | 
En el país el $16 \%$ de las viviendas ocupadas están ubicadas en territorios étnicos donde habita 1,027 hogares por vivienda, mientras el $84 \%$ de viviendas están en territorios no étnicos y en cada una habita 1,033 hogares promedio. En Antioquia la vivienda ocupada en territorios étnicos es muy baja: 2,6\%, mientras en territorios no étnicos está el $97 \%$ de los hogares con un promedio de habitación de 1,028 hogares por vivienda.

Tabla 9. Número de hogares unipersonales para el total en el área rural dispersa censada

\begin{tabular}{lcr}
\hline \multirow{2}{*}{ Dominio } & \multicolumn{2}{c}{ Total área rural dispersa censada } \\
\cline { 2 - 3 } & Total hogares & Hogares unipersonales \\
\hline Total nacional & 1.543 .134 & 294.911 \\
\hline Antioquia & 180.819 & 36.010 \\
\hline
\end{tabular}

Fuente: Datos del Censo Nacional Agropecuario, Anexo 3, tercera entrega

Las cifras de hogares unipersonales son muy significativas, considerando los pocos que habitan el área rural. En Colombia corresponde al $19 \%$ del total y en Antioquia al $20 \%$.

Tabla 10. Número de hogares con adultos mayores y número de personas mayores de 60 años para el total en el área rural dispersa censada

\begin{tabular}{cccc}
\hline \multirow{2}{*}{ Dominio } & \multicolumn{3}{c}{ Total área rural dispersa censada } \\
\cline { 2 - 4 } & Total hogares & $\begin{array}{c}\text { Hogares con adultos } \\
\text { mayores }\end{array}$ & Persona igual o mayor a 60 años \\
\hline Total nacional & 1.543 .134 & 613.916 & 707.445 \\
\hline Antioquia & 180.819 & 73.294 & 77.349 \\
\hline
\end{tabular}

Fuente: Datos del Censo Nacional Agropecuario, Anexo 3, tercera entrega

$39,8 \%$ de los hogares en Colombia tiene entre sus integrantes adultos mayores. En Antioquia esa cifra es del 40,5\%. Otro indicador del envejecimiento de la población rural, lo que tiene profundas repercusiones para el desarrollo del sector. 
Tabla 11. Número de hogares con personas menores de 15 años y número de personas menores de 15 años para el total en el área rural dispersa censada

\begin{tabular}{cccc}
\hline \multirow{2}{*}{ Dominio } & \multicolumn{3}{c}{ Total área rural dispersa censada } \\
\cline { 2 - 4 } & Total hogares & Hogares con menores de 15 años & Total menores de 15 años \\
\hline Total nacional & 1.543 .134 & 784.434 & 1.368 .516 \\
\hline Antioquia & 180.819 & 93.204 & 142.805 \\
\hline
\end{tabular}

Datos del Censo Nacional Agropecuario, Anexo 3, tercera entrega

50,8 \% de los hogares en Colombia tiene entre sus integrantes menores de 15 años. En Antioquia esa cifra es del 51,5\%.

Tabla 12. Índice de envejecimiento ${ }^{12}$ para el total en el área rural dispersa censada

\begin{tabular}{cccc}
\hline Dominio & $\begin{array}{c}\text { Total área rural } \\
\text { dispersa censada }\end{array}$ & $\begin{array}{c}\text { Total área rural dispersa censada } \\
\text { en territorios de grupos étnicos }\end{array}$ & $\begin{array}{c}\text { Total área rural dispersa censada } \\
\text { sin territorios de grupos étnicos }\end{array}$ \\
\hline Total Nacional & 51,7 & 25,2 & 61,4 \\
\hline Antioquia & 54,2 & 16,4 & 56,4 \\
\hline
\end{tabular}

Datos del Censo Nacional Agropecuario, Anexo 3, tercera entrega

En Colombia el índice de envejecimiento en los territorios sin grupos étnicos es 61,4 frente al 25,2 de los territorios étnicos. Lo anterior se explica porque las comunidades étnicas socioculturalmente son tradicionales y tienden a auto preservarse, por tanto, es común que las personas permanezcan en sus territorios en el tiempo. En Antioquia, en el área rural dispersa, el índice está levemente por encima del nacional, pero concentra, junto a Cundinamarca, el mayor porcentaje de adultos mayores. Es importante resaltar, cómo se observa en la Figura 4, que la mayoría de la población adulta está concentrada en las zonas con mayores actividades, ante todo agrícolas en el país, lo que plantea un panorama preocupante en cuanto a la sostenibilidad en el mediano plazo de la actividad de la pequeña economía agrícola.

\footnotetext{
${ }^{12}$ Es un indicador que compara el número de personas mayores de 60 años con los menores de 15 años e indica el nivel de disminución de la población absoluta en el mediano plazo (30 años).
} 


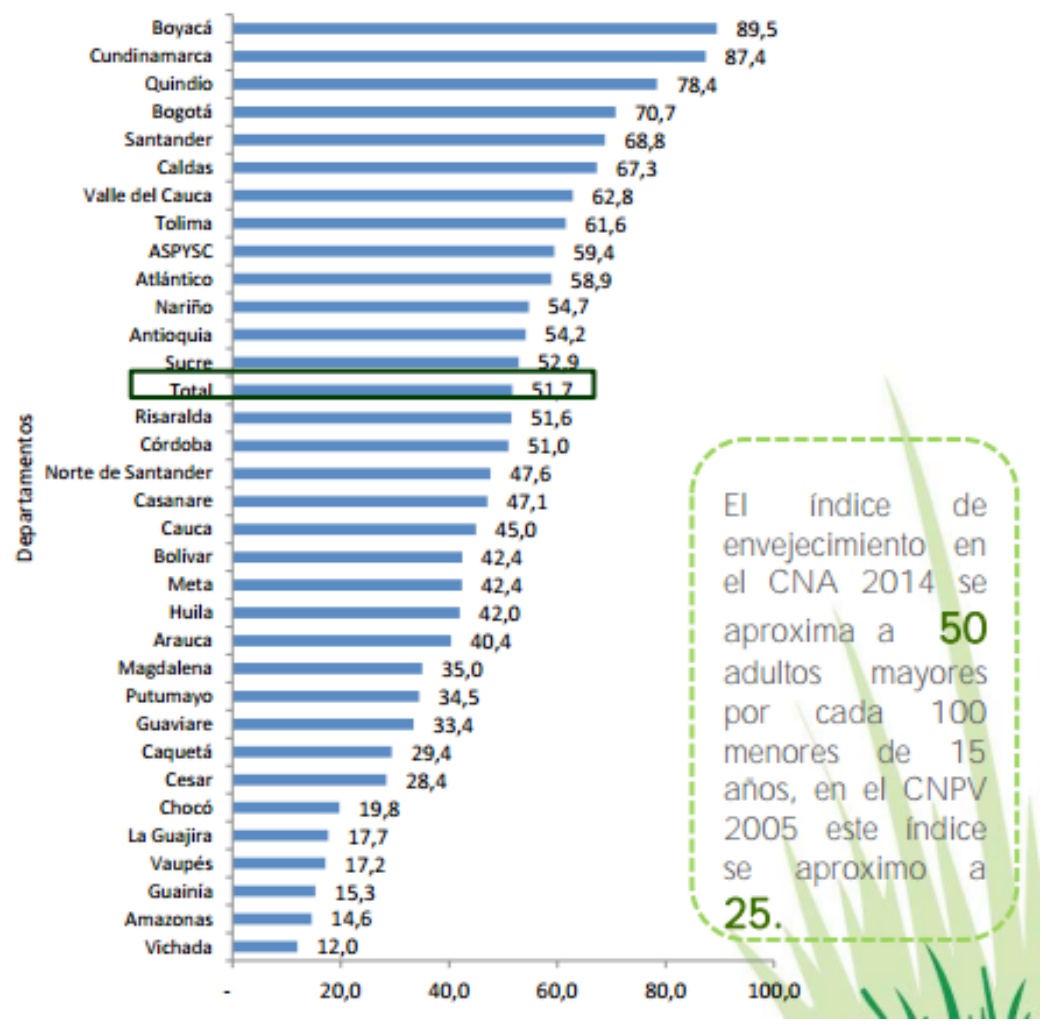

Gráfica 8. Índice de envejecimiento de la población residente en el área rural. Fuente: Tomado de Censo Nacional Agropecuario (2015) p. 42

\section{Conclusiones}

Si se permite hacer una generalización del caso de Antioquia, se observa que las ciudades colombianas crecieron de forma desordenada y desproporcionada en sólo dos décadas, engrosadas por migraciones de campesinos desposeídos, despojados y victimizados que huyendo de la violencia llegaron a las zonas más pobladas buscando refugio, poniendo en jaque a una institucionalidad débil, incapaz de brindar condiciones de seguridad protectora. Personas que no han podido adaptarse a una vida urbana e instituciones sin una vida urbana capaz de responder a las demandas de esta población, porque no posee la estructura necesaria ni la capacidad operativa para prestarles servicios, ni ofrecerles opciones de desarrollo de sus capacidades, convirtiendo las ciudades en centros caóticos por lo que viene del campo, por lo que surge del campo como 
guerra, como injusticia y como miseria. Estas poblaciones asentadas en las periferias capitalinas ya no quieren regresar, pero tampoco terminan de adaptarse a la vida urbana, las instituciones han mostrado incapacidad de ofrecerles oportunidades de hacer el tránsito de la ruralidad a una vida urbana digna. Las oportunidades en las ciudades, particularmente en el caso de Medellín, no crecieron a la misma velocidad de las demandas de estas poblaciones migrantes, por tanto, la capacitación de esas poblaciones y el cambio en su naturaleza social es un trabajo muy complejo en el camino de la recuperación nacional en el marco del posconflicto.

De otro lado, el poco apoyo y abandono estatal a través del tiempo a las zonas rurales, marcado por la centralización de los recursos y el desinterés de los demás niveles territoriales, la escasa oferta de programas sociales y económicos para el fortalecimiento de las unidades productivas y para la generación de otras fuentes de ingreso a los campesinos y la ausencia de políticas adecuadas a los territorios de educación, salud y vivienda, constituyen condiciones estructurales que impiden el desarrollo del campo colombiano. Una ruralidad paulatinamente desocupada que ha favorecido los procesos de acumulación que conduce a que potenciales ociosos, una población envejecida y empobrecida que profundiza las brechas regionales y aún locales sea el panorama del campo colombiano, tomando como referente el caso de Antioquia, de cara a la implementación de la reforma rural integral.

El conflicto armado colombiano ha marcado de manera muy negativa al sector rural, afectando directamente las dinámicas de vida de las personas que habitan en territorio, reconfigurando sus espacialidades, definiendo la destinación del suelo y en últimas determinando el carácter de las demás zonas del país ya que los continuos desplazamientos de población rural le han dado un sello a las ciudades colombianas, afectando su crecimiento y sostenibilidad y cooptando la capacidad del Estado para hacer frente a las necesidades de la población.

\section{Referencias bibliográficas}

Acosta, C., Ordóñez, L. y Parra-Peña, R. (2013). Pobreza, brechas y ruralidad en Colombia. Coyuntura Económica, Vol XLIII, No 1, Fedesarrollo, 15-36.

Acuerdo Final. (2016). Acuerdo General para la Terminación del Conflicto y la Construcción de una Paz Estable y Duradera. La Habana: Mesa de Conversaciones.

Arboleda, J.C., Vásquez, F. y Elejabarrieta, F. (2014). Memoria e imaginarios sociales del conflicto colombiano: desmemorias y acontecimientos, de como olvidar recordando. Barcelona: Universidad Autónoma de Barcelona.

Brand, M., Cárdenas, A.V. y Restrepo, N. (2015). Coexistencia y uso estratégico de los modelos de participación política en los procesos de transformación urbana en Colombia. El caso 
de Medellín. Estudios de Derecho, 72 (160), 217-242.

Conferencia Episcopal de Colombia y Universidad de Antioquia. (2001). Desplazamiento Forzado en Antioquia. Bogotá: Secretariado Nacional de Pastoral Social.

Corte Constitucional de Colombia. (2004). Sentencia T-025 de 2004. Agencia Oficiosa en Tutela. Departamento Administrativo Nacional de Estadística (DANE). (2015). Censo Nacional Agropecuario. Bogotá: Departamento Administrativo Nacional de Estadística.

Departamento Administrativo Nacional de Estadística (DANE). (2015). Proyecciones de Población Nacionales y Departamentales 2006 - 2020. Bogotá: Departamento Administrativo Nacional de Estadística.

Dirección de Desarrollo Rural Sostenible (DDRS). (2014). Definición de Categorías de Ruralidad. Bogotá: Departamento Nacional de Planeación - DNP.

Programa de las Naciones Unidas para el Desarrollo (PNUD). (2011). Colombia rural: Razones para la esperanza. Informe Nacional de Desarrollo Humano. Bogotá: INDH PNUD.

Departamento Nacional de Planeación (DNP). (2015). El campo colombiano: un camino hacia el bienestar y la paz. Misión para la transformación del campo. Bogotá: Nuevas Ediciones SA.

Fajardo, D. (2002). La tierra y el poder político; la reforma agraria y la reforma rural en Colombia. Food and Agriculture Organisation. Reforma Agraria: Colonización y Cooperativas, 1.

Gaviria, C.F. y Muñoz, J.C. (2007). Desplazamiento forzado y propiedad de la tierra en Antioquia, 1996 - 2004 . Lecturas de Economía, 66 (enero - junio), 9-46.

Gobernación de Antioquia (2013). Valores, representaciones y capital social en Antioquia. Medellín: Mesa Editores.

Gobierno de Colombia. (20 de mayo de 2015). Red Nacional de Información. Recuperado de https://rni.unidadvictimas.gov.co/

Grupo de Memoria Histórica. (2013). ¡Basta Ya! Colombia: Memorias de guerra y dignidad. Bogotá: Imprenta Nacional.

Henderson, J. (2012). Víctima de la globalización: la historia de cómo el narcotráfico destruyó la paz en Colombia. Bogotá: Siglo del Hombre Editores.

Ibáñez, A.M., Moya, A. y Velásquez, A. (2006). Hacia una política proactiva para la población desplazada. Bogotá: USAID.

Ibáñez, A. y Velásquez, A. (2008). El impacto del desplazamiento forzoso en Colombia: condiciones socioeconómicas de la población desplazada, vinculación a los mercados laborales y políticas públicas. Santiago de Chile: Comisión Económica para América Latina y el Caribe CEPAL.

Machado, A. (2011). La tierra y el desarrollo humano. Hechos de Paz No. 57, 12-16.

Medina, M.A. (3 de diciembre de 2015). ¿Qué es la Misión para la Transformación del Campo y qué propuso? El Espectador.

Naranjo, G. (2004). Ciudades y desplazamiento forzado en Colombia. El "reasentamiento de hecho" y el derecho al restablecimiento en contextos conflictivos de urbanización. En M.N. Bello, Desplazamiento forzado: dinámicas de guerra, exclusión y desarraigo (pp. 279310). Bogotá: Universidad Nacional de Colombia.

Osorio, F. \& Lozano, F. (2014). Proceso de reconstrucción vital de población desplazada por la violencia en Colombia. Universitas Humanística V. 47, No 47, 75-85.

Pérez S, M.G. (1994). Investigación cualitativa II: retos e interrogantes: técnicas y análisis de datos. Madrid, España: La Muralla.

Ramírez, J.C. y De Aguas, J. (2017). Configuración territorial de las provincias de Colombia: ruralidad y redes. Bogotá: Comisión Económica para América Latina y el Caribe CEPAL.

Restrepo S, N. (2013). Historia social y económica de Antioquia en el siglo XX. Medellín, Colombia.

Restrepo S, N. (2016). Empresariado antioqueño y sociedad, 1940-2004: Influencia de las élites patronales de Antioquia en las políticas socioeconómicas. Taurus.

Rodríguez H, J. y Alzate, V. (2015). Atención a las víctimas de la violencia por los gobiernos 
territoriales: entre la gestión de políticas y el burocratismo rampante. Administración y Desarrollo, 45 (2), 224-238.

Rojas N, J.E. (2016). Postacuerdo y gestión territorial. Bitácora Urbano Territorial 26 (2), 135146.

Ruiz, E., Arrubla, D. y Sanabria, P. (2013). Envejecimiento y vejez en Colombia. Bogotá: Profamilia.

Uribe López, M. (2013). La Nación vetada: estado, desarrollo y guerra civil en Colombia. Bogotá: Universidad Externado de Colombia.

Villa, J.D. \& Insuasty, A. (2015). Significados en torno a la reparación, la ayuda humanitaria, la indemnización y la restitución en víctimas del conflicto armado en el municipio de San Carlos. Ágora USB, 15 (2), 419-445.

Zuluaga, M. (22 de enero de 2016). Alarma por falta de vivienda. El Tiempo. 